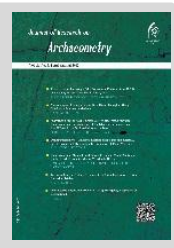

\title{
Evaluation of the Impact of Iron on Structural deterioration of Chrome Leather in Buried Conditions, Based on Degradation Indices in FTIR Spectra
}

\author{
Alireza Koochakzaei ${ }^{1 \star}$, Mahsa Saidi Mehrabad² \\ ${ }^{1}$ Assistant Professor, Faculty of Applied Arts, Tabriz Islamic Art University, Tabriz, IRAN \\ ${ }^{2}$ B.A in Conservation of Cultural and Historical Artifacts, Tabriz Islamic Art University, Tabriz, IRAN
}

Received: 09/11/2019

Accepted: 24/12/2019

\begin{abstract}
As leather production is an ancient industrial activity, historical leathers represent an important part of any society's cultural materials. However, since leather is made from collagen fibers that are susceptible to many degradation factors, leather artifacts have been remained less often than other historical materials. Wide variety application of leather, imposes a particular set of conditions, which can bring about deterioration in the leather. In general, deterioration of leather is a chemical process in which there are a great number of contributing factors. Iron and its corrosion products are among the effective factors in the degradation of leathers, especially in buried specimens. This factor, in combination with the leather and tanning chemistry, leads to very diverse and complex degradation mechanisms. Therefore, the aim of this study is to evaluate the effects of iron corrosion products on leather deterioration. Accordingly, a buried leather sample obtained from historic "Khosravi" Leather Factory, Tabriz Islamic Art University, was examined. Based on appearance, the leather was buried in the vicinity of the iron and its corrosion products. Different parts of leather show the possibility of penetration of different amounts of iron or its corrosion products. Structural evaluation of different parts of the leather and their deterioration was performed by spot test of iron (using potassium ferrocyanide), leather ash measurement, Micro xray fluorescence $(\mu \mathrm{XRF})$, Ultraviolet-visible (UV-Vis) and Fourier-transform infrared (FTIR) spectroscopy and microscopic examination. FTIR spectra were also fitted to the Gaussian function. The results showed that this sample was tanned with chromium salts and, probably, lime was used for dehairing. Examination of leather showed that the amount of iron varied in different parts of leather. In other words, a part of the leather has been in direct contact with iron and, over time, corrosion products have penetrated the leather structure. This has led to differences in the amount of iron in different parts of leather. Structural changes in different parts of leather were investigated using degradation indices in FTIR spectra. The hydrolysis degree of the polypeptide chains can be semiquantified using the amide $\mathrm{I}$ /amide $\mathrm{II}$ band intensity ratio $\left(\mathrm{I}_{\mathrm{AI}} / \mathrm{I}_{\mathrm{AII}}\right)$, which is about $1.25-1.30$ for new leathers and increases with deterioration. The triple helical structure integrity can be also evaluated by peak absorbance ratio of amide III and $1450 \mathrm{~cm}^{-1}$, which is equal to or higher than 1 for the intact collagen triple helix and around 0.5 for denatured collagen. Moreover, the relative position of amide I and amide II bands $\left(\Delta \mathrm{V}=\mathrm{V}_{\mathrm{AI}}-\mathrm{V}_{\mathrm{AII}}\right)$ is corresponding to the collagen gelatinization process, and the value is around $90-100 \mathrm{~cm}-1$ for new leathers. The carbonyl index at $1740 \mathrm{~cm}^{-1}$ also shows the oxidation of collagen. Accordingly, examination of the structural properties of different parts of the leather showed that as the amount of iron in the leather
\end{abstract}

*Corresponding author: alireza.k.1989@gmail.com 
increased, the integrity of triple-helical structure of collagen collapsed (decrease in $\mathrm{I}_{\mathrm{AIII}} / \mathrm{I}_{1450}$ ) and its hydrolysis increased (increase in $\mathrm{I}_{\mathrm{AI}} / \mathrm{I}_{\mathrm{AII}}$ ). And it also has increased collagen oxidation (increase in $\left.\mathrm{I}_{1740} / \mathrm{I}_{\mathrm{AI}}\right)$. However, the results did not show a significant change in the index of collagen gelatinization $(\Delta v)$.

Keywords: Leather, Collagen, Chromium tanning, Degradation of leather, Iron, FTIR 


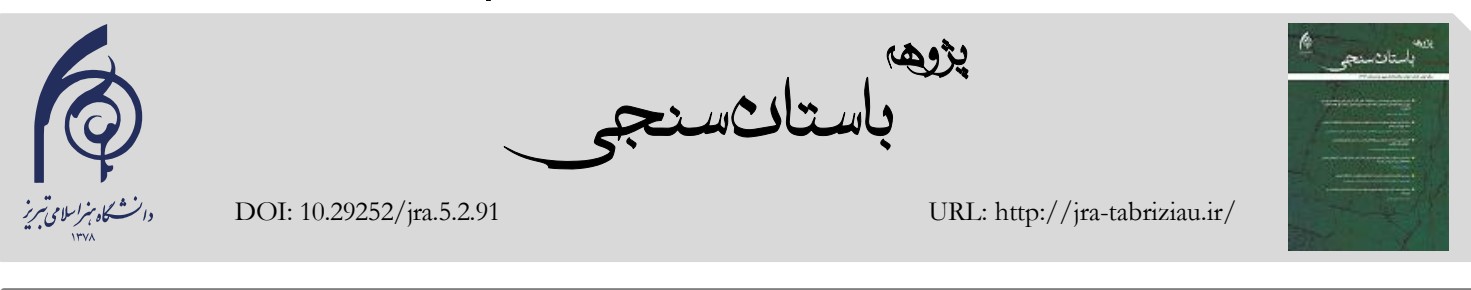

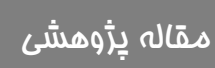

\section{ارزيابى تأثير آهن بر فرايند تخريب ساختارى خرم كروم در}

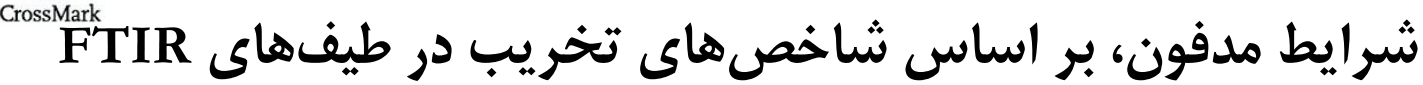

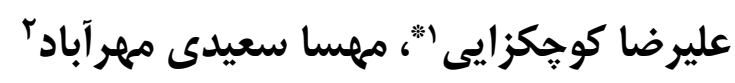

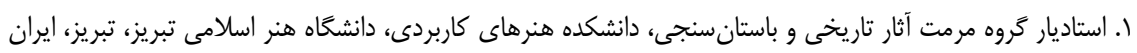

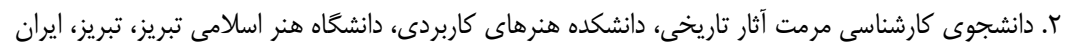

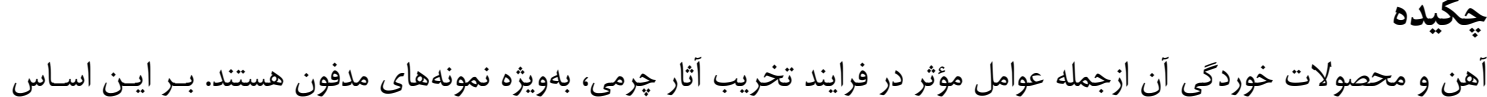

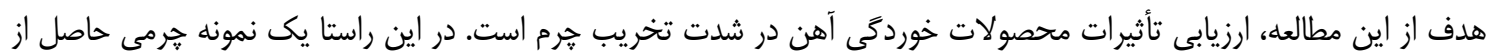

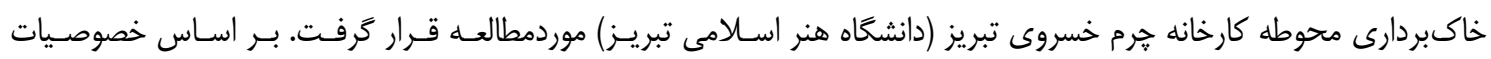

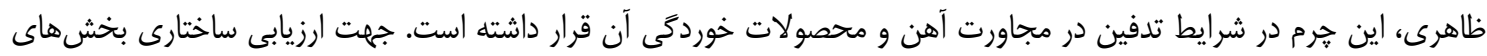

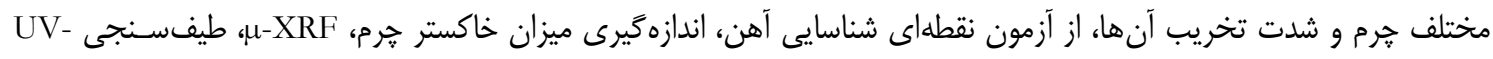

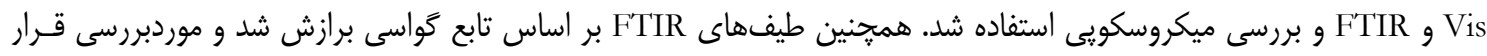

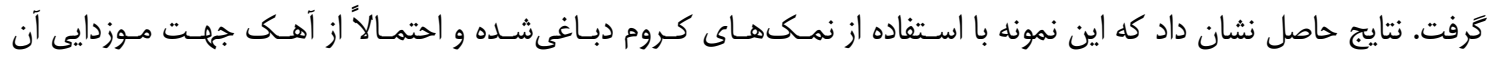

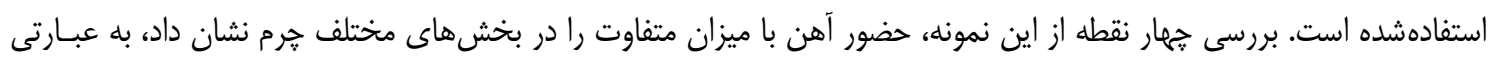

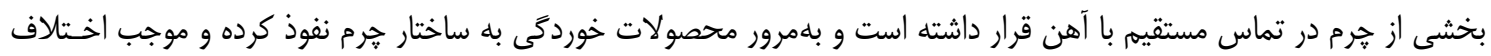

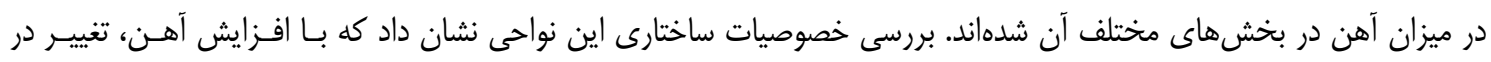

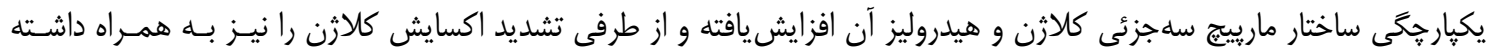

وازًَان كليدى: هرم، كلازن، دباغى كروم، تخريب هرم، آهن، FTIR

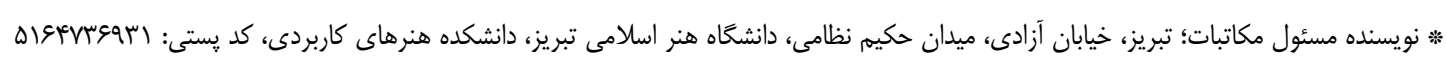

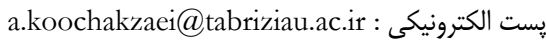
CC حق نشر متعلق به نويسنده(كان) است و نويسنده تحت مجوز Creative Commons Attribution License به مجله اجازه مى دهد مقاله خاب شده را با ديخران به اشتراك بكذارد منوط بر اينكه حقوق مؤلف اثر حفظ و به انه انتشار اوليه مقاله در اين مجله اشاره شود. 
كردن آمونياك را دارند. نتيجهُ اين واكنشها با هر اسـيد

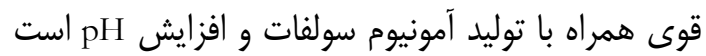

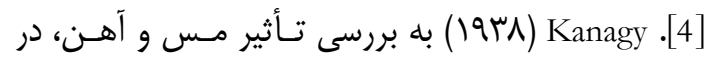

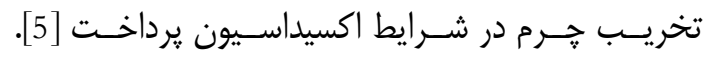

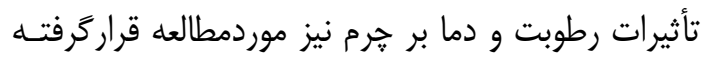

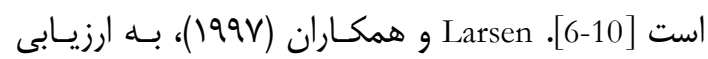

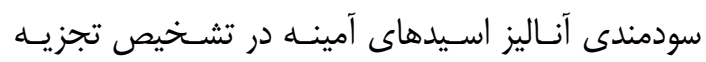

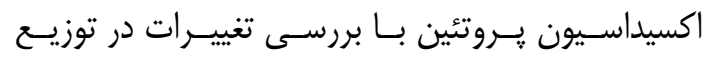

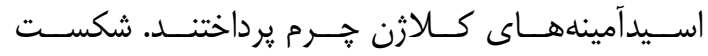

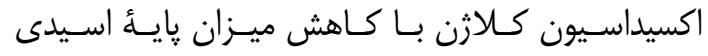

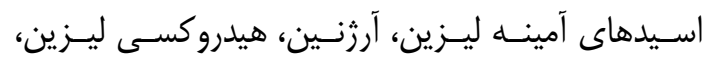

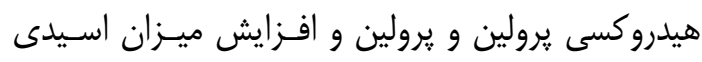

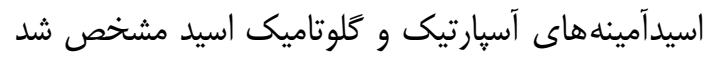

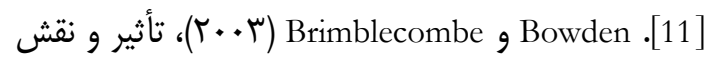

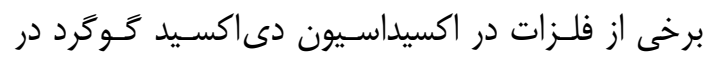

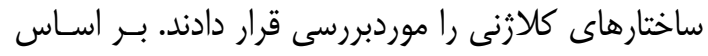

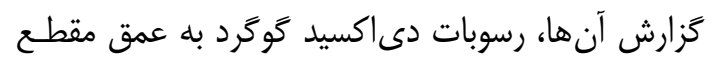

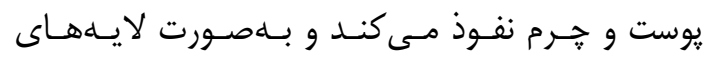

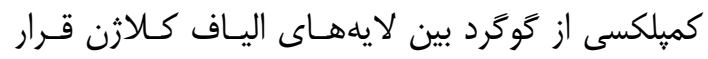
مى گيرد. سولفات در اين رسوبات ناشـى از اكسيداسـيون

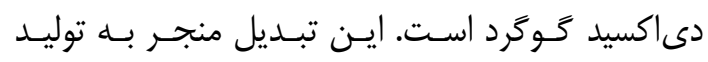

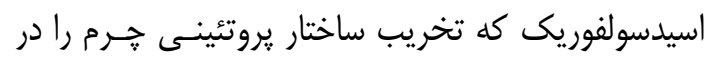

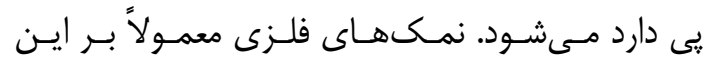

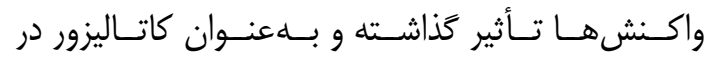
اكسيداسيون دى اكسيد گوظرد مطرحانـد [12]. Creangă

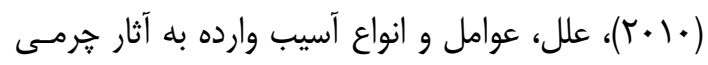

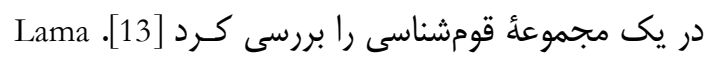

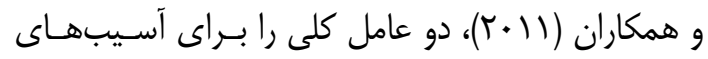

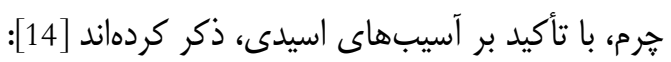

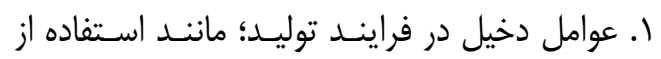

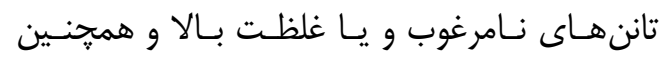

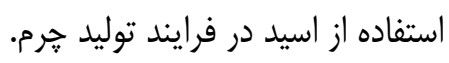

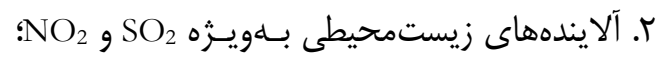
كه جذب جرمهاى با دباغى گيـاهى شـده و و امكـان تشكيل اسيد، بلويثه

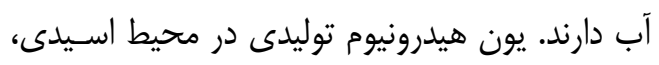

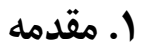

هرم و محصولات يوستى همـواره تحـت تـأثير آسـيب و مقده

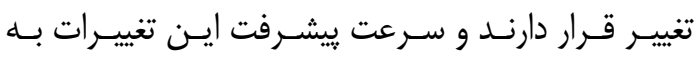

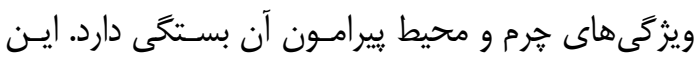

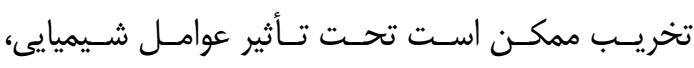

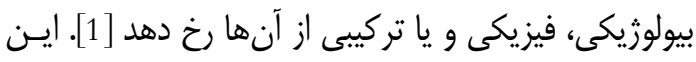

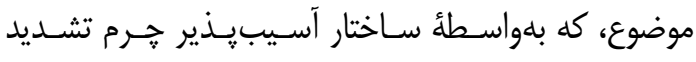

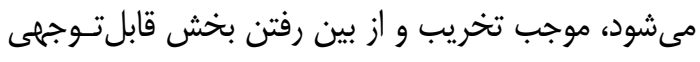

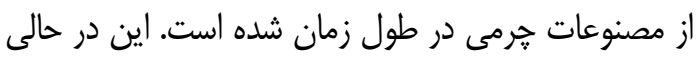

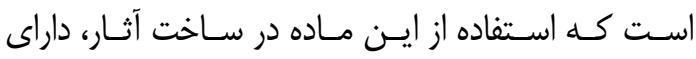
ييشينهاى بسيار طولانى بوده است. بالينوجـود همجنـان

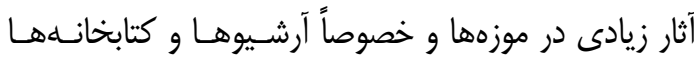

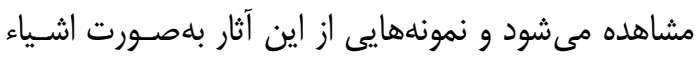

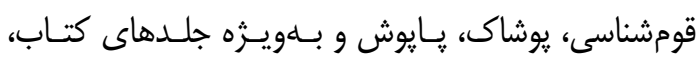
زينتبخش اين مجموعلها هستند.

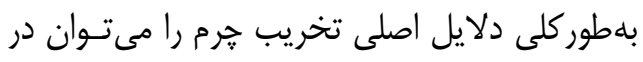
ه دسته شامل رطوبت، حرارت، تخريب شيميايى، عوامل

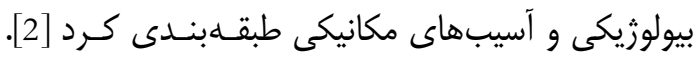

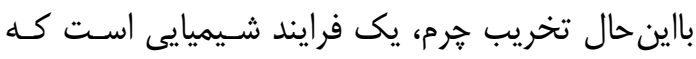
عوامل متعددى در شكل گيرى و بيشـرفت آن تأثير تـــار

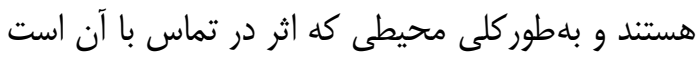

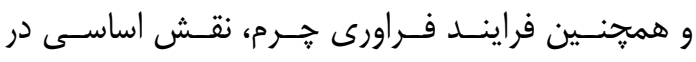

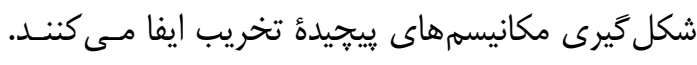

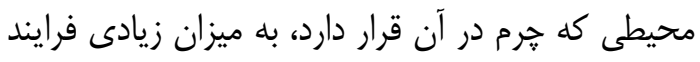

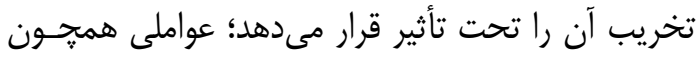

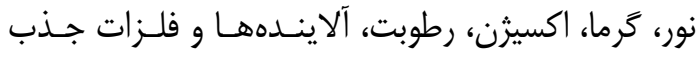

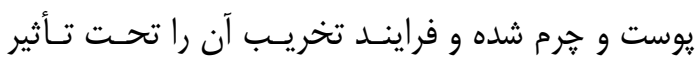

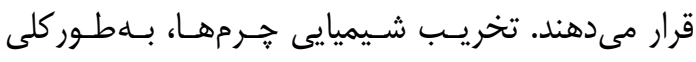

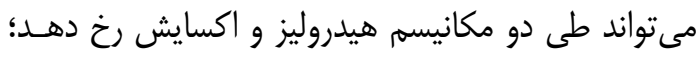

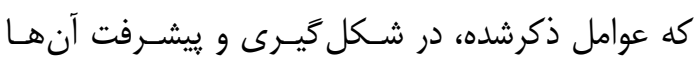
مؤثر هستند [3]. مطالعات در زمينه فرايندهاى تخريب هرم و عوامل

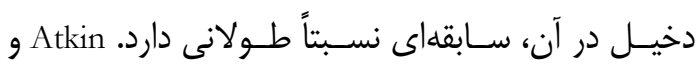
يول Thompson

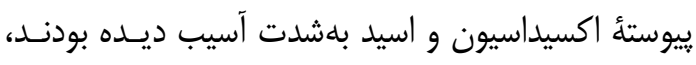

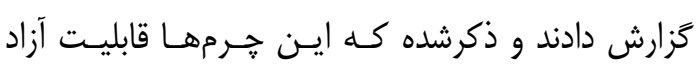

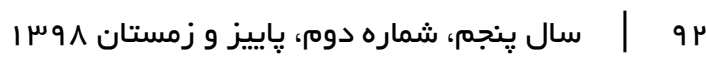




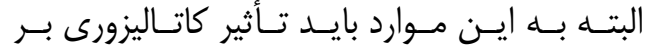

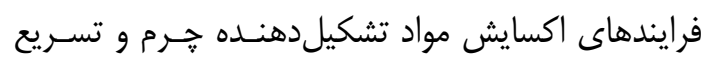
هيدروليز جرم را نيز افزود. در برخى مطالعات، نقش آهن آهن در هيدروليز كلازثن موردبحث قراركر فتته است. مطالعات

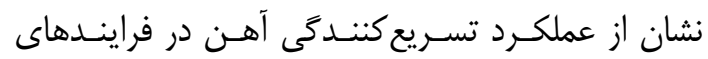

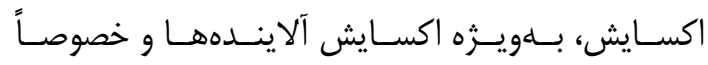

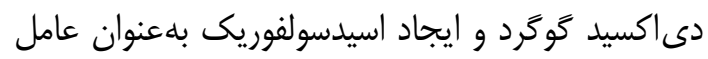

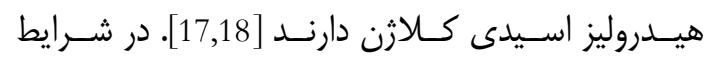

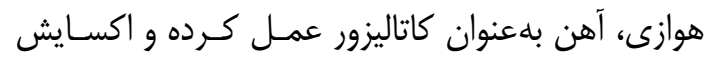

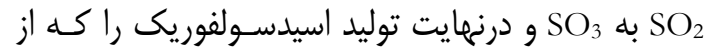
معهمترين عوامل تخريب هرم است، تسريع مى كند [12].

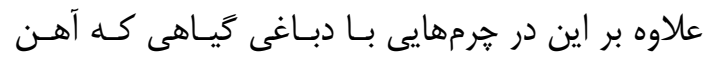

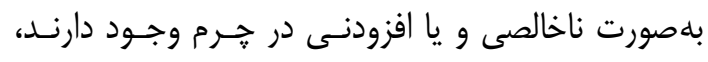
بهلعنوان كاتاليزور در اكسايش كاتكول بــــ ارتـو-كينـون

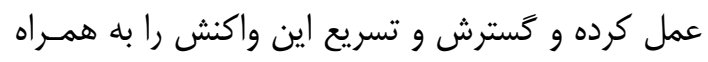

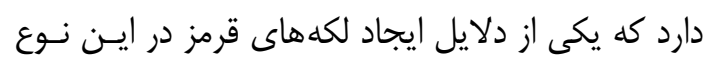

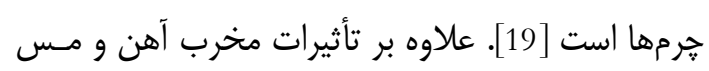

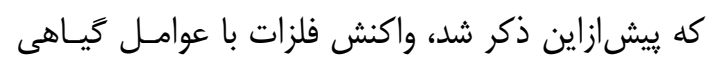

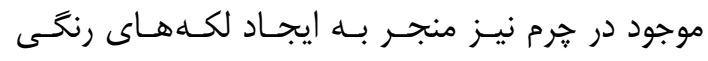

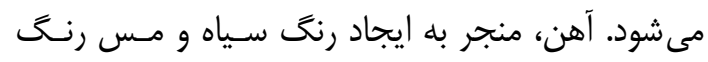

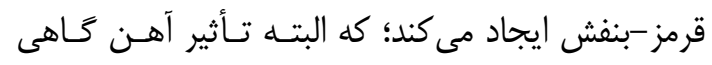

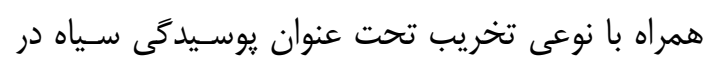

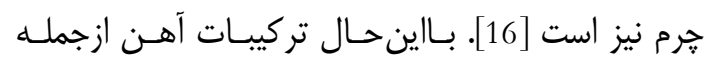

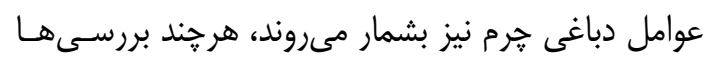

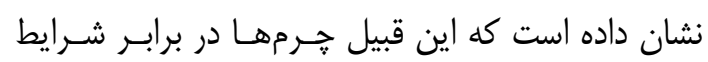

تخريب حساس بوده و مستعد اكسايش هستند [20].

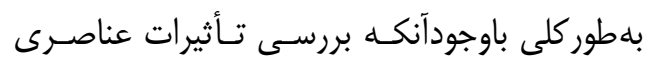

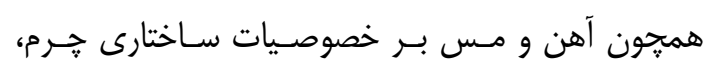

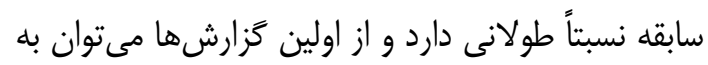

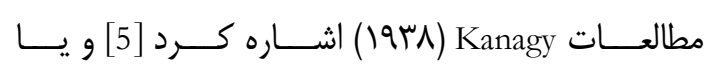

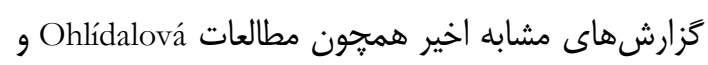

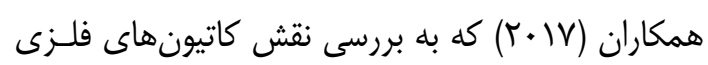

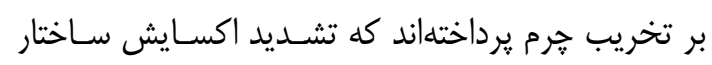

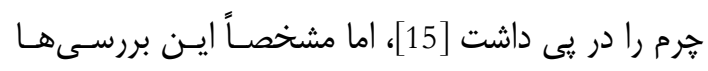

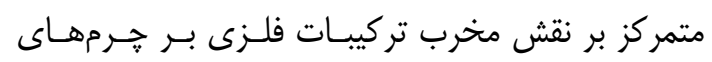

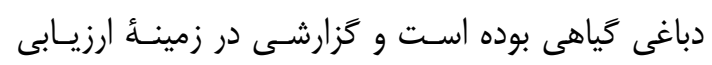

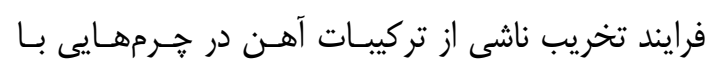
$9 \mu$
موجب هيدروليز كلازن خرم مىشود.

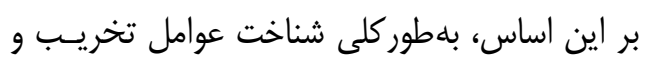

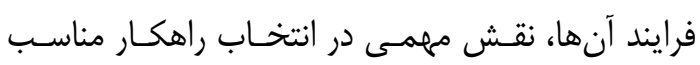

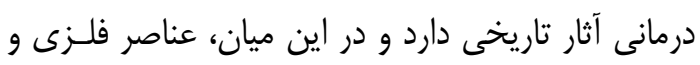

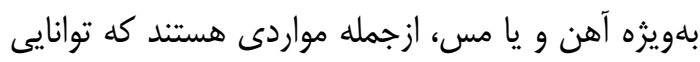

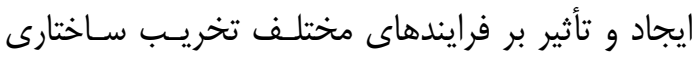

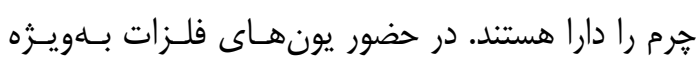

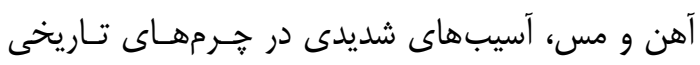

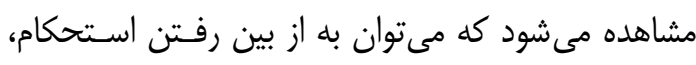

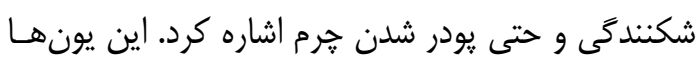

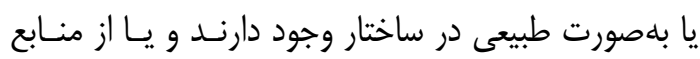

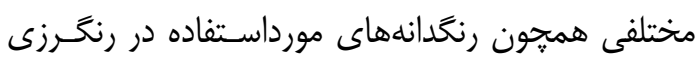

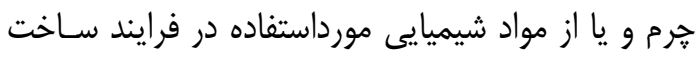
و يا از طريق تماس مستقيه هرم با قطعـات فلـزى وارد مارد

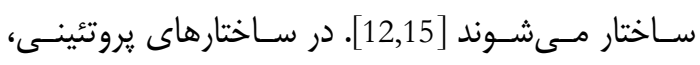

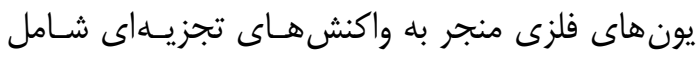

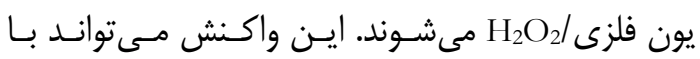

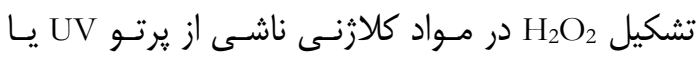

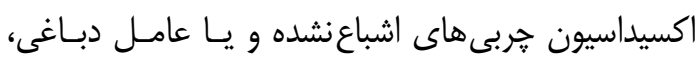

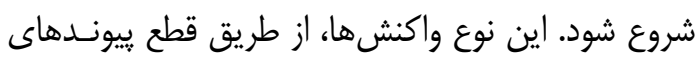

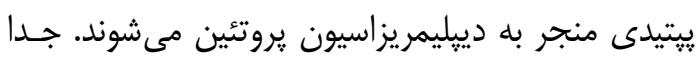
از يونهاى تأثير كذار، آهن (II) و خصوصاً مس (II) ايسن مئن

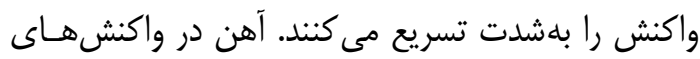
اكسايش-كاهش نقش دارد و مىتواند بلهعنوان كاتاليزور

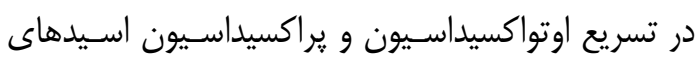

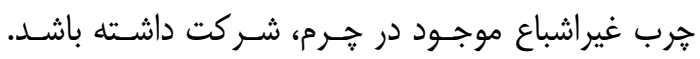

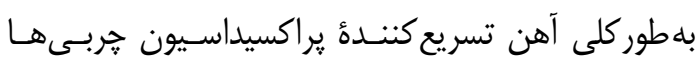

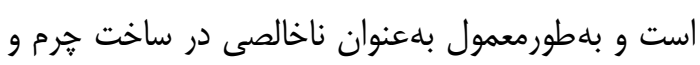

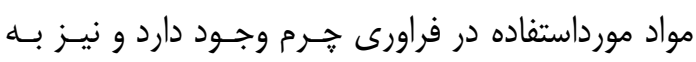
سهولت با تركيبات آلى كىليت مى شود [116].

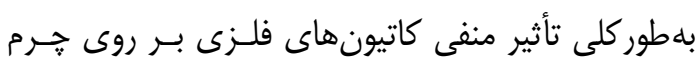
ممكن است در موارد زير آشكار شود [15]:

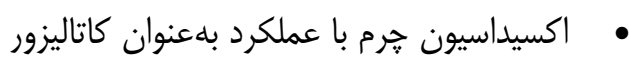

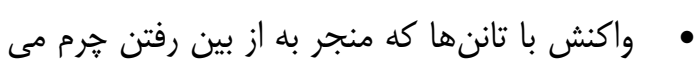
شود. فشار كريستاليزاسيون كه در اثر تبلـور مجـدد برخسى

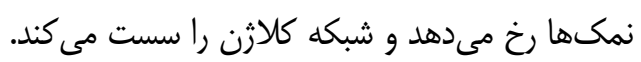


هماندازه، با فاصلهاى ثابـت و در رديـفهــاى مـوازى را

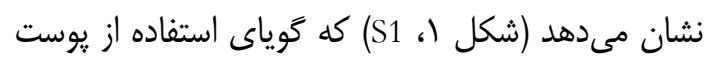

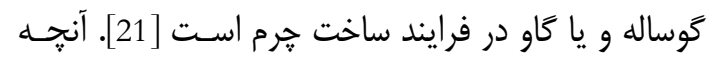
از خصوصيات ظاهرى جرم مشهود است، تماس مستقيم

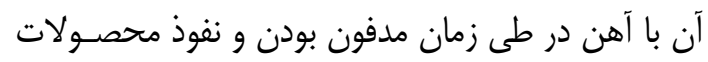

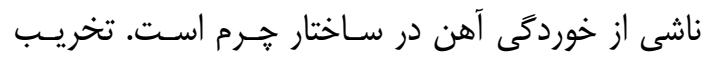

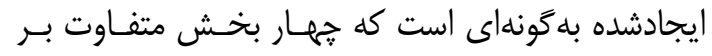

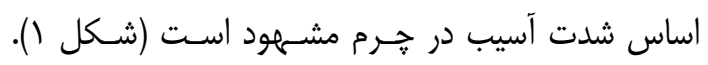

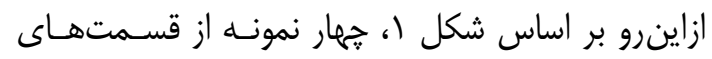

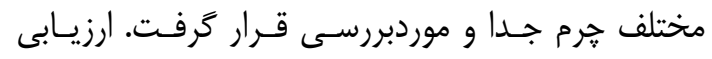

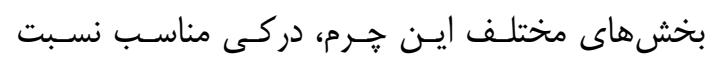

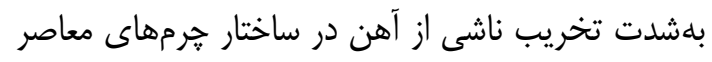

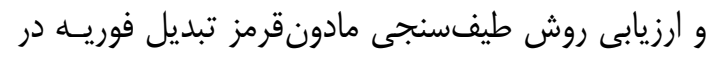

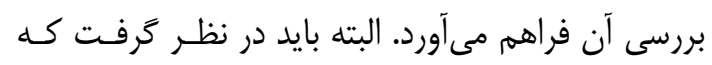

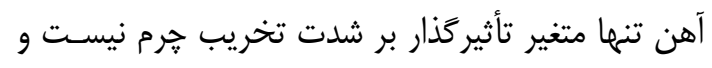

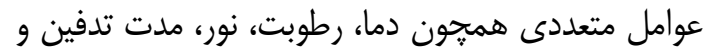

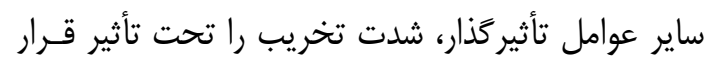

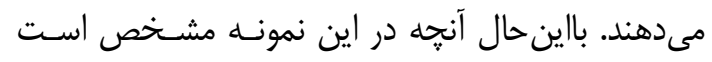

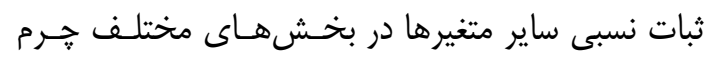

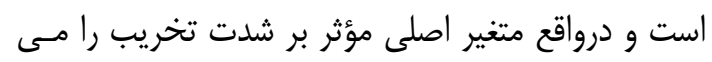
توان ميزان متفاوت آهن در ساختار خرم دانست.
دباغى كروم منتشر نشده است. بالينحال بخـش كَسـترده

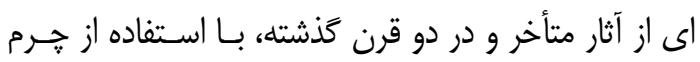

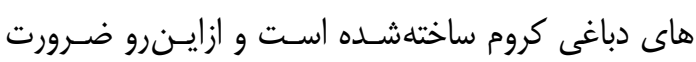

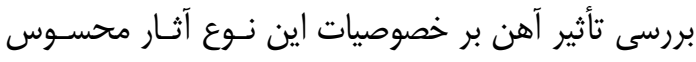

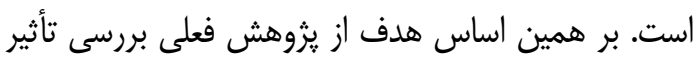

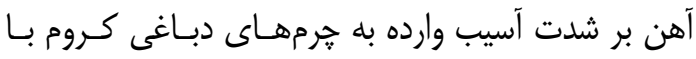
بررسى يك نمونه موردى حاصل از خاكبردارى محوطـهـ كارخانه تاريخى خرم خسروى تبريز است.

\section{r. (r مواد و روشها}

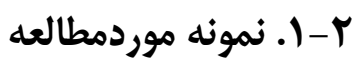
جهت بررسى تأثير تركيبات آهن بـر تخروديسب سـاختارى

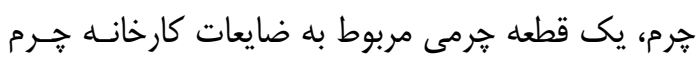
خسروى تبريز موردبررسى قرار كَرفت. اين كارخانه كه از فران نخستين كارخانههاى خرمسازى ايران محسوب مى شعودي،

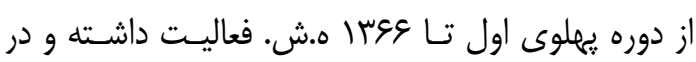

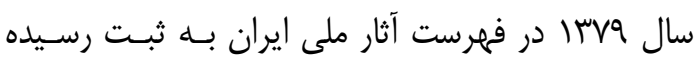

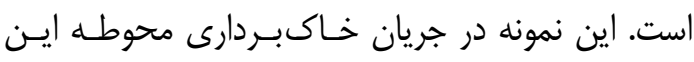

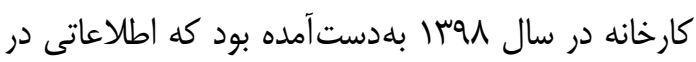

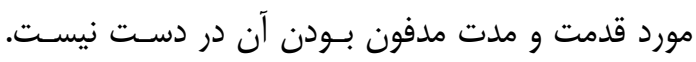
بررسى الكوى رويش مــو در ايـن جـــرم، حفــرات تقريبـاً

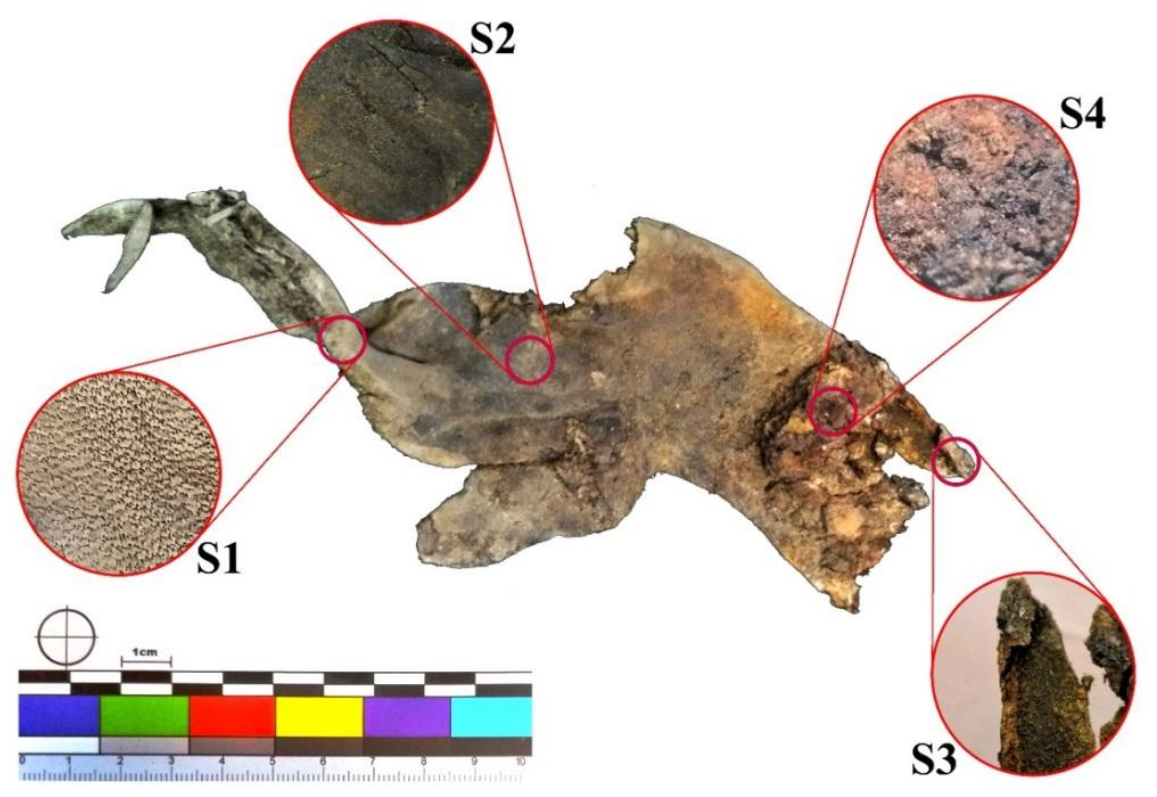

شكل ا: بقاياى جرم موردبر رسى و موقعيت نمونههاى جداشده جهت انجام مطالعات Fig. 1: Leather residue studied and sampling location for analysis 
جهار نمونه از بخشهاى مشخص شده קـرم جـدا شــــ و

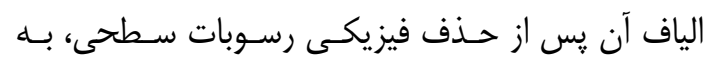

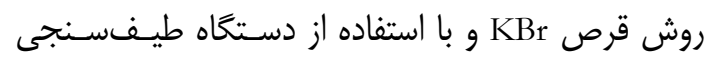
مادونقرمز تبديل فوريه، مدل FT/IR-680Plus سـاخت

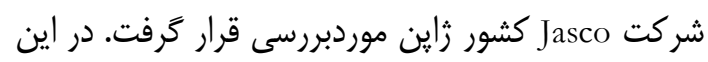

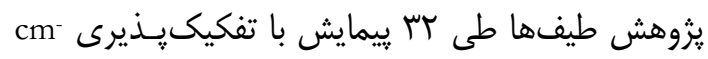

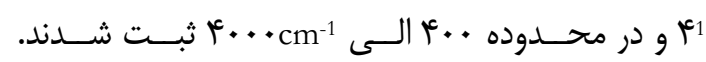
همجنين جهت بررسى يارامترهاى تخريب در طيـفهـا،

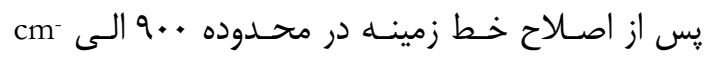

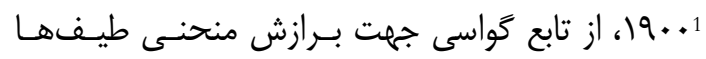

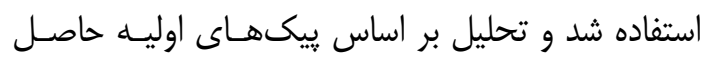
شده انجام گرفت.

\section{ץ-0. تعيين ميزان خاكستر}

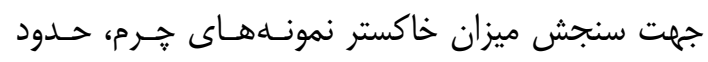

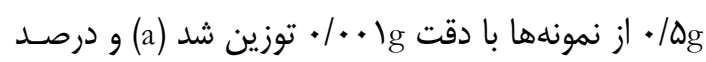

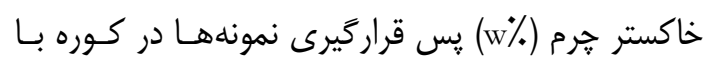

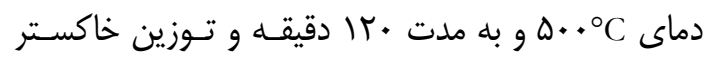

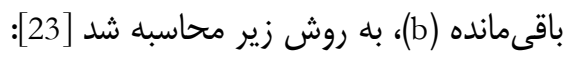

$$
w \%=\frac{b}{a} \times 100
$$

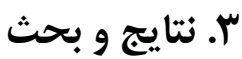

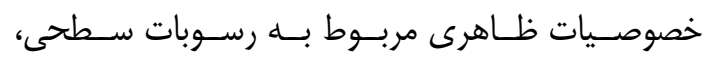

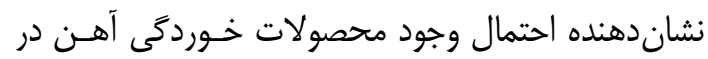

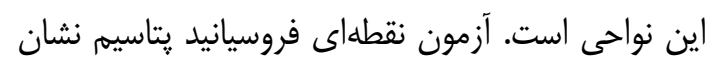

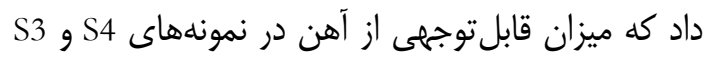

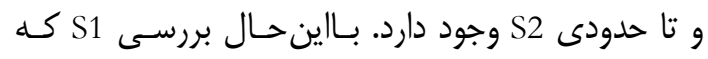
ازنظر خصوصيات ظاهرى آسيب كمترى را متحمل شدى داره،

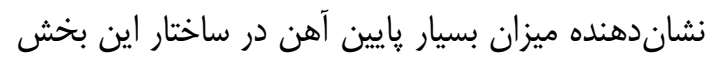

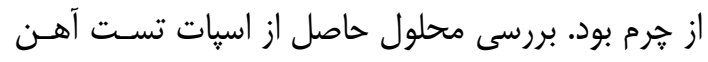

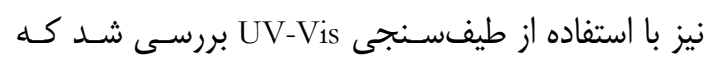

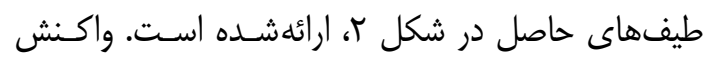
فروسيانيد يتاسيم با يون آهن در شرايط اسيدى منجر بـ آنه

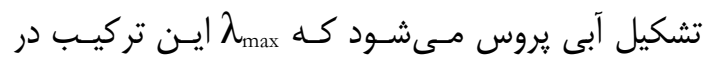

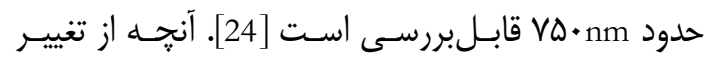
شدت جـذب در حـدود VD.nm مشـهود اسـت، ميـزان

\section{}

بلهمنظور بررسى عناصر تركيبات معدنى موجود در ساختار

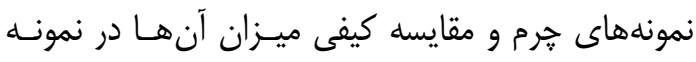

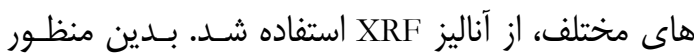
مقطع عرضى نمونـهـهـاى جـرم بــا اسـتفاده از دسـتخاه

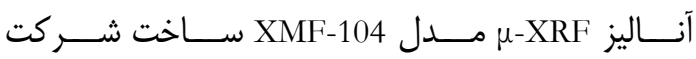
Unisantis

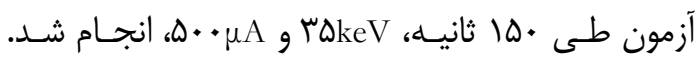

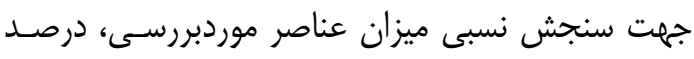

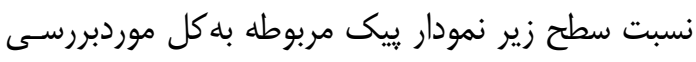

قرار گرفت.

r-r. آزمون نقطهاى شناسايى آهن و طيف Uنجى UV-Vis

جهت ارزيابى آزمون نقطهاى وجود آهن در ساختار نمونه

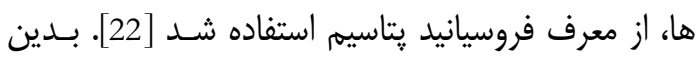

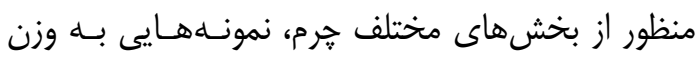

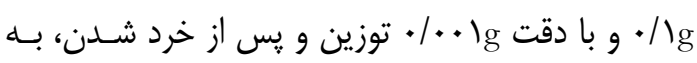

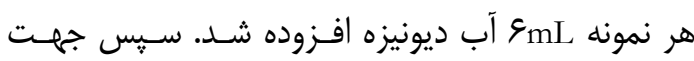

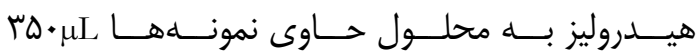

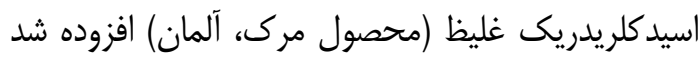

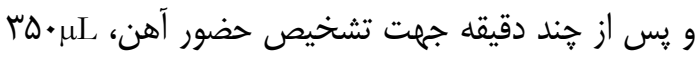
معرف فروسيانيد يتاسيم (محصول مرك، آلمان) به لونه آله

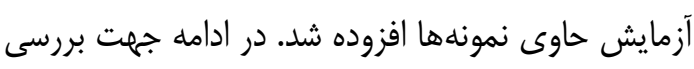

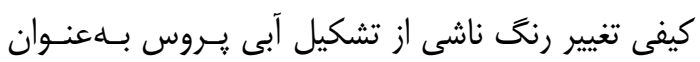

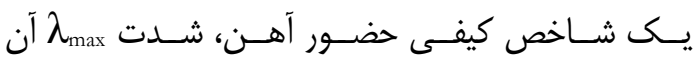

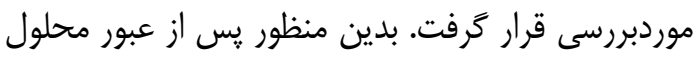

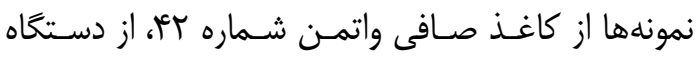

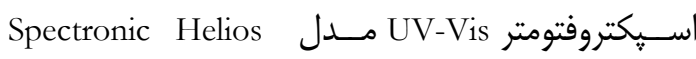
Thermo Fisher Scientific Alpha

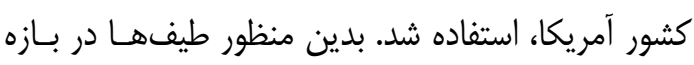

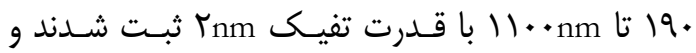

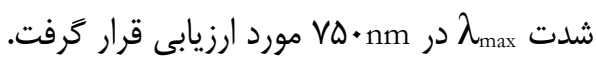

FTIR جهت بررسى تغييرات ساختارى و ارزيابى شـاخصهـاى تخريب از طيفسنجى FTIR استفاده شد. بـدين منظـور 


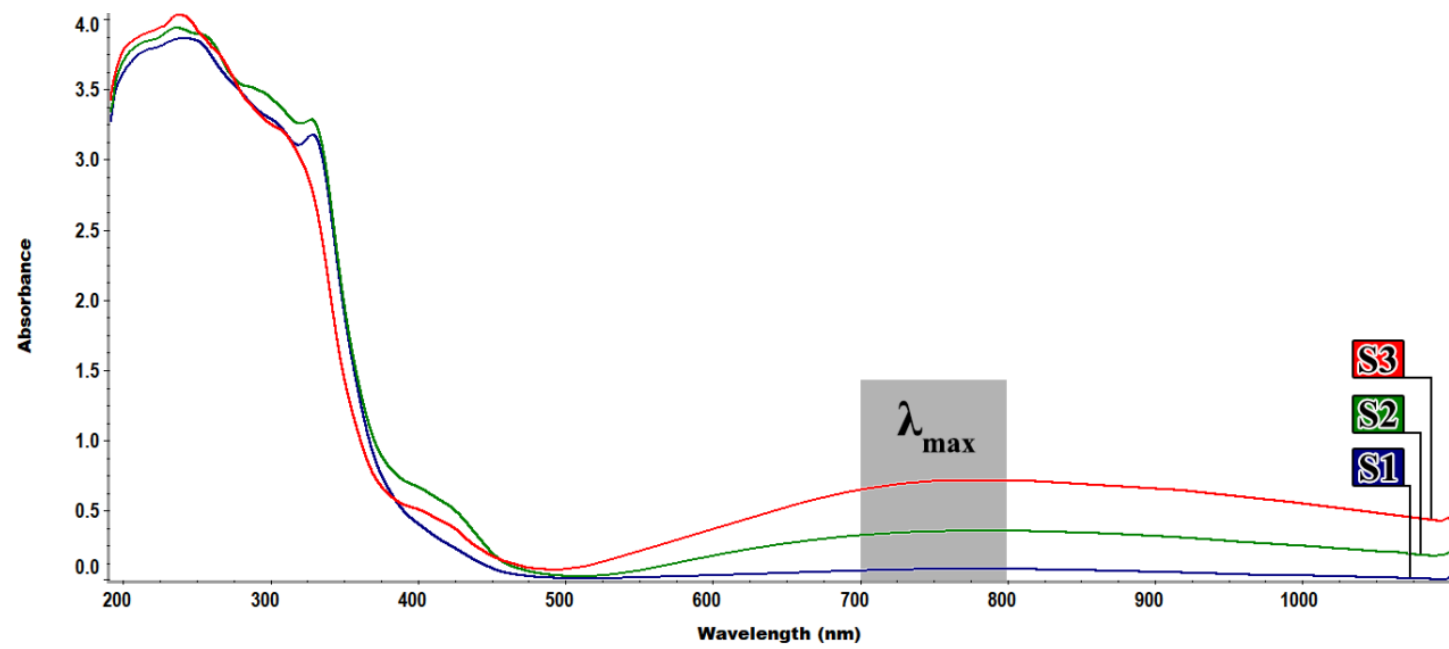

شكل ז: طيفهاى UV-Vis محلول حاوى آبى يروس حاصل از آزمون نقطهاى حضور آهن در نمونهاى جرم

Fig. 2: UV-Vis spectra of Prussian blue solution obtained from iron spot test on leather samples

ارتباط مستقيهم با ميزان تجمع آهن در ساختار خرم دارد.

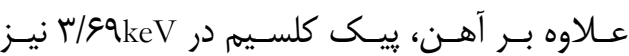
مشاهده مىشود [25] كـهـ احتمـال اسـتفاده از آهـــ در

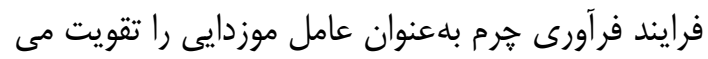

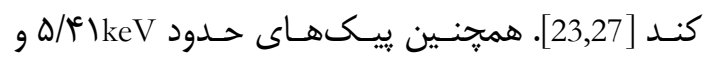

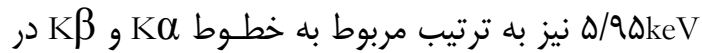

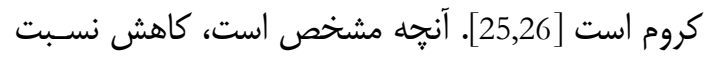

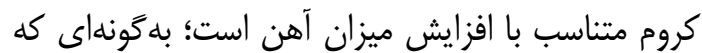

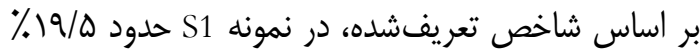

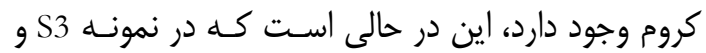

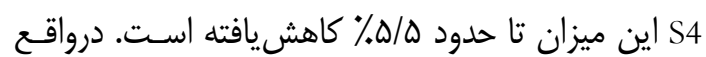

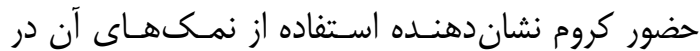

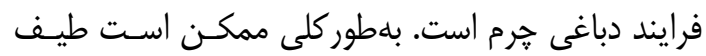

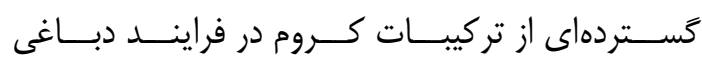

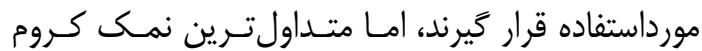
مورداستفاده در دبـاغى و صـنعت جـرمسـازى، سـولفات كروم (III) بوده است [28].

آنجه از دادههاى ب-XRF مشخص اسـت، افـزايش

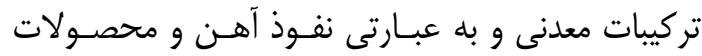

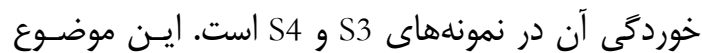
بهخوبى در ميزان خاكستر نمونههاى هـرم نيـز مشهمود

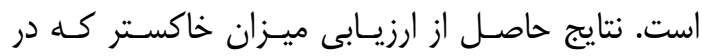

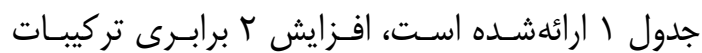

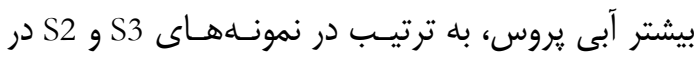

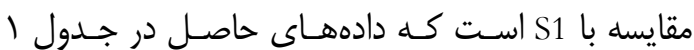

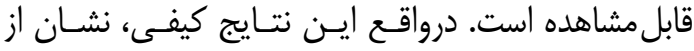

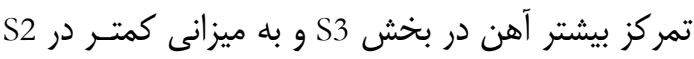

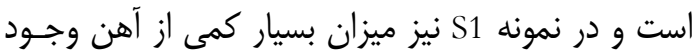

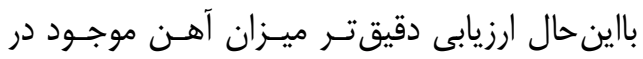

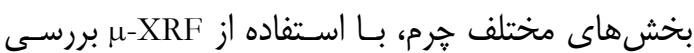

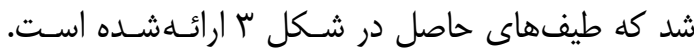

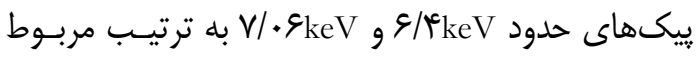

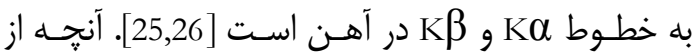

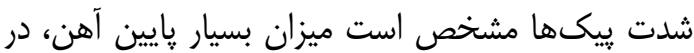
بخش S1 هرم است. بالينحال شدت يِيك در نمونههاى

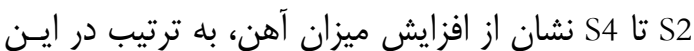

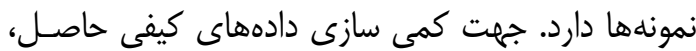

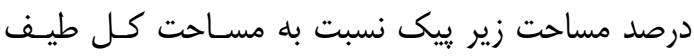
محاسبه شد كه نتايج در جدول ل ارائهشدهاند. بر اسـاس

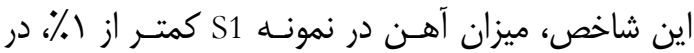

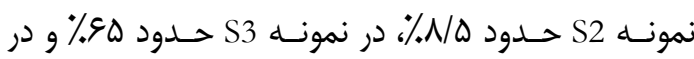

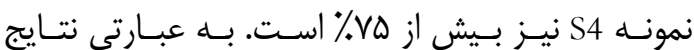

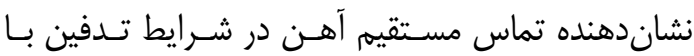
بخش S4 و نفوذ محصولات خوردگى آن به ساختار خرم

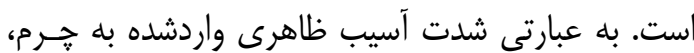




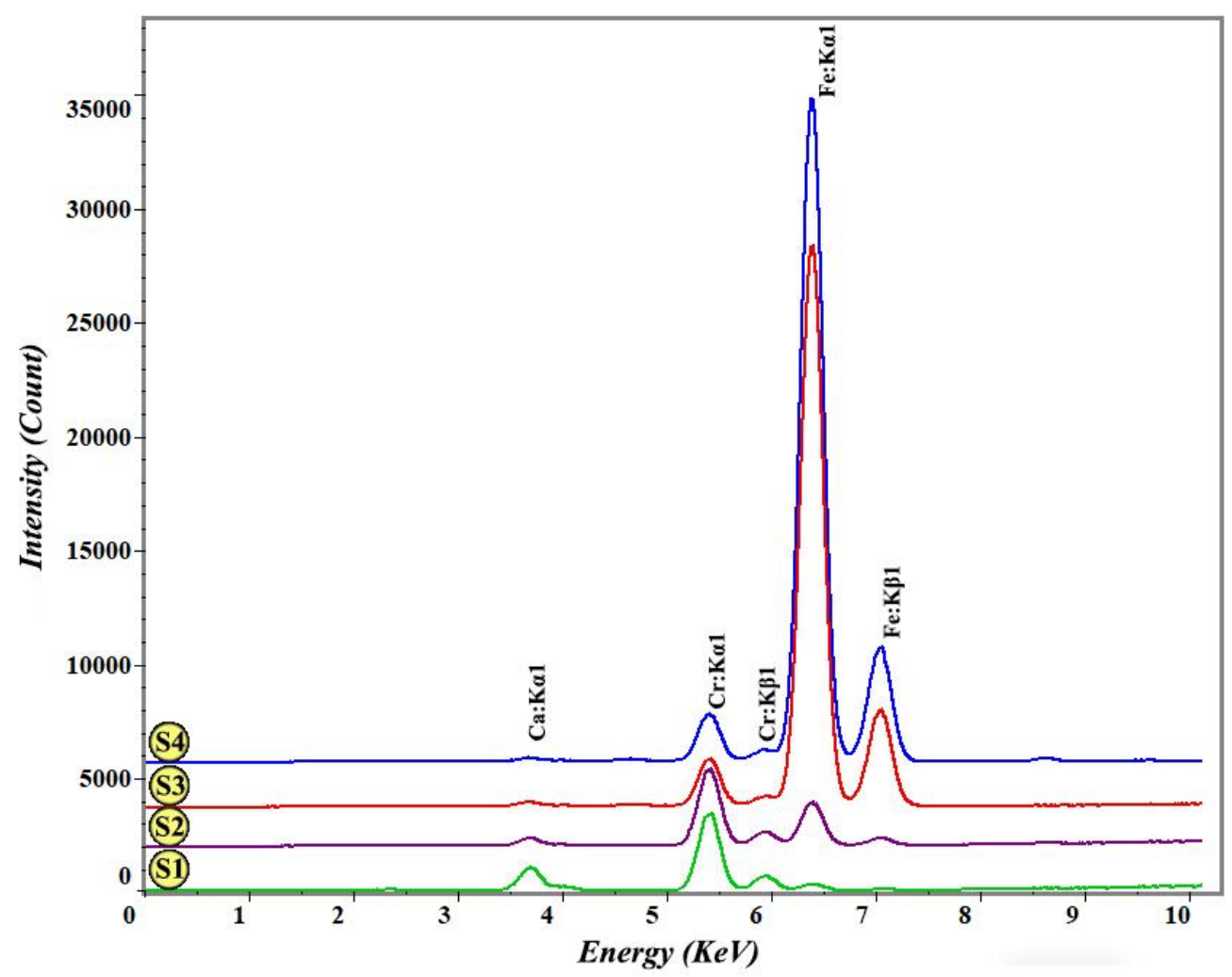

شكل ץ: طيفهاى M-XRF لايه ميانى نمونههاى خرم

Fig. 3: $\mu$-XRF spectra of the corium layer of leather samples

ميكروسكويى الياف كلاثن را نيز به همراه داشته باشـند. در حقيقت تخريب شديد مواد كلاثنى، تشكيل ساختارى شبيه به زنجيرهاى از دانههاى مرواريد را در الياف كلازن

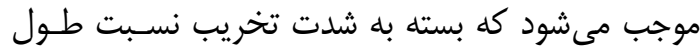

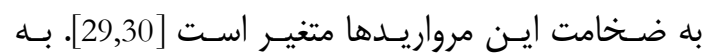
عبارتى اين نسبت را مىتوان يـك شـاخص تخريـب در

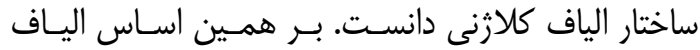

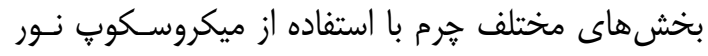
عبورى بررسى شد. در نمونه S4 ساختار هرم بلهَونسهاى

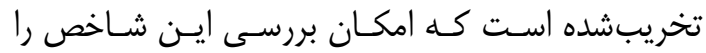

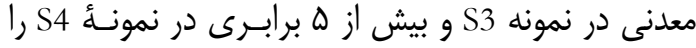

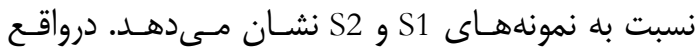
افزايش ميزان محصولات خوردگى آهن و سـاير عناصـر

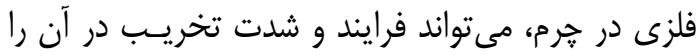

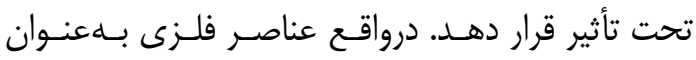

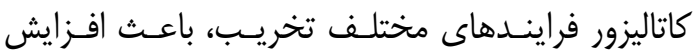

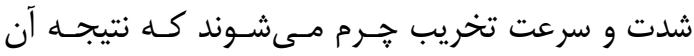

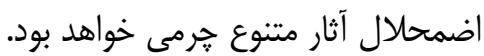
بـهـطـور كلى فراينـدهاى تخريـب در سـاختار مــواد

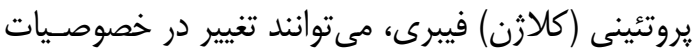

جدول (. نتايج حاصل از UV-Vis ،

Table 1. results of $\mu$-XRF and UV-Vis spectroscopy and determination of ash content (\%)

\begin{tabular}{|c|c|c|c|c|c|}
\hline \multirow[b]{2}{*}{$\begin{array}{c}\text { خاكستر (\%) } \\
\text { Ash content (\%) }\end{array}$} & UV-Vis & \multicolumn{3}{|c|}{$\mu$-XRF } & \multirow[b]{2}{*}{$\begin{array}{l}\text { نمونه } \\
\text { Sample }\end{array}$} \\
\hline & $\begin{array}{c}\lambda_{\max }: V \Delta \cdot \mathrm{nm} \text { شدت } \\
\text { Intensity in } \lambda_{\max } 750 \mathrm{~nm}\end{array}$ & $\begin{array}{l}\text { مجموع (\%) } \\
\text { Total (\%) }\end{array}$ & $\begin{array}{l}\text { آهن (\%) } \\
\text { Iron (\%) }\end{array}$ & $\begin{array}{c}(\%) \text { كروم (\%) } \\
\text { Chromium (\%) }\end{array}$ & \\
\hline 11.56 & 0.122 & 20.35 & 0.91 & 19.44 & S1 \\
\hline 11.19 & 0.477 & 27.06 & 8.48 & 18.58 & S2 \\
\hline 20.30 & 0.709 & 70.09 & 64.6 & 5.49 & S3 \\
\hline 57.37 & - & 81.25 & 75.73 & 5.52 & S4 \\
\hline
\end{tabular}




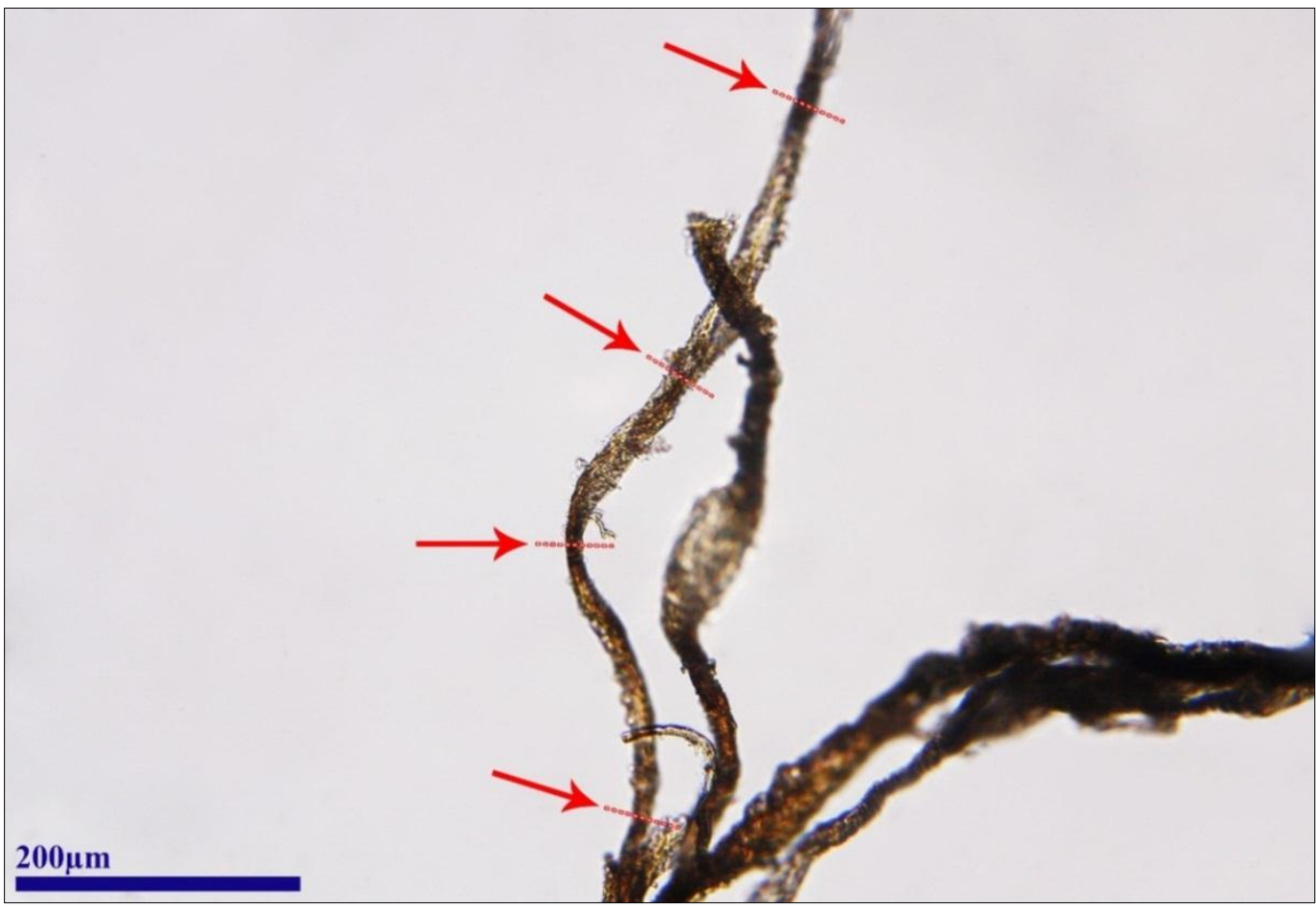

شكل عا: بررسى ميكروسكويى ساختار زنجيره مرواريدى در الياف كلاثن نمونه

Fig. 4: leather fiber of S3 sample forming the pearls on a string structure

خوردگى آهن به شكل اكسيد، همراه با خاك محل دفن، بخش قابلتوجهى از سـاختار نمونسه S4 را تشـكيل داده است. در اين طيف، نوارهاى جذبى در حدود

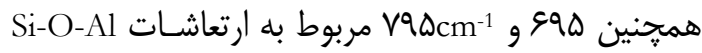

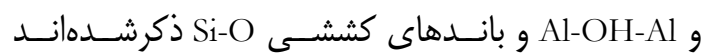
[31,32]. همجنين ارتعاش كششى نامتقـارن Si-O-Si در كر حدود جل

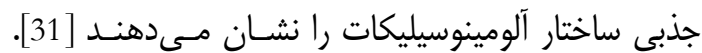

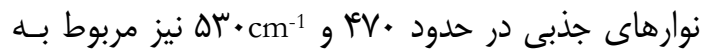

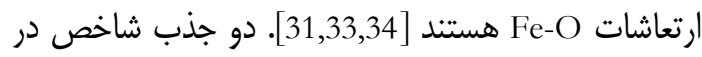

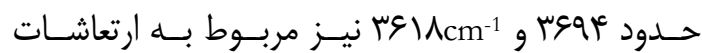

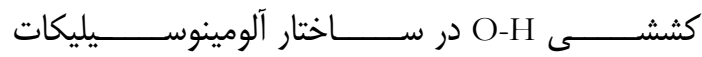

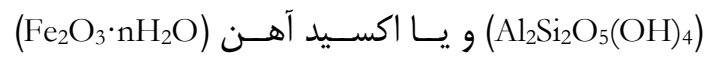
است [31,35,36]

فراهم نمى آورد. در ميان نمونسهــاى S1، S2 و S3،

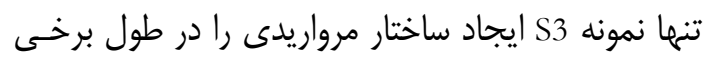

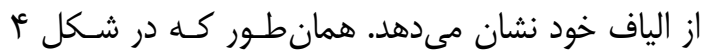
مشخص است، حدفاصل بخشهاى عالامت گذارى شـده بهعنوان مرواريد و نقاط مشخصشده تحت عنوان بروانه
فراهم نمى آورد. در ميـان نمونسههــاى S1، S2 و S3، تنهــا

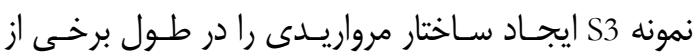

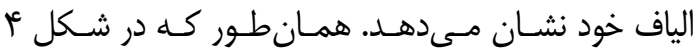

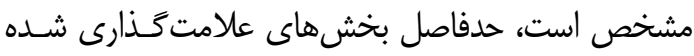
بلهعنوان مرواريد و نقاط مشخصش بده تحت عنوان يروانـه

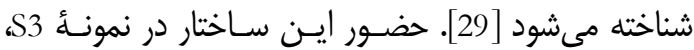

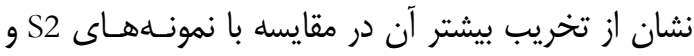

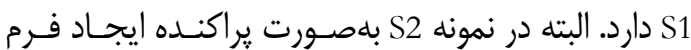

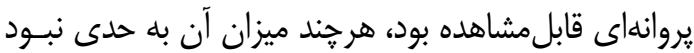
كه امكان بررسى اين شاخص تخريب را فراهم آورد.

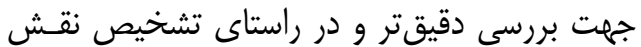

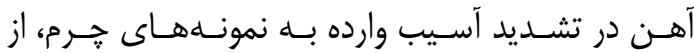

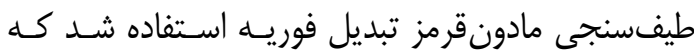
طيفهاى حاصل در شكل ه ارائهشدهاند. طيـف مربـوط فئس به نمونهٔ S4 باطور كلى اختلاف واضحى نسبت به ساصاير

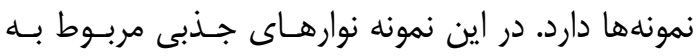
تركيبات معدنى به شكلى مشخص قابل مشـاهده اسـت. خصوصيات طيفى، تركيبى از ساختارهاى اكسيد آهـن و و

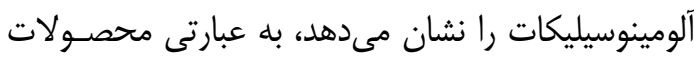

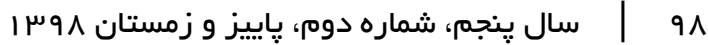




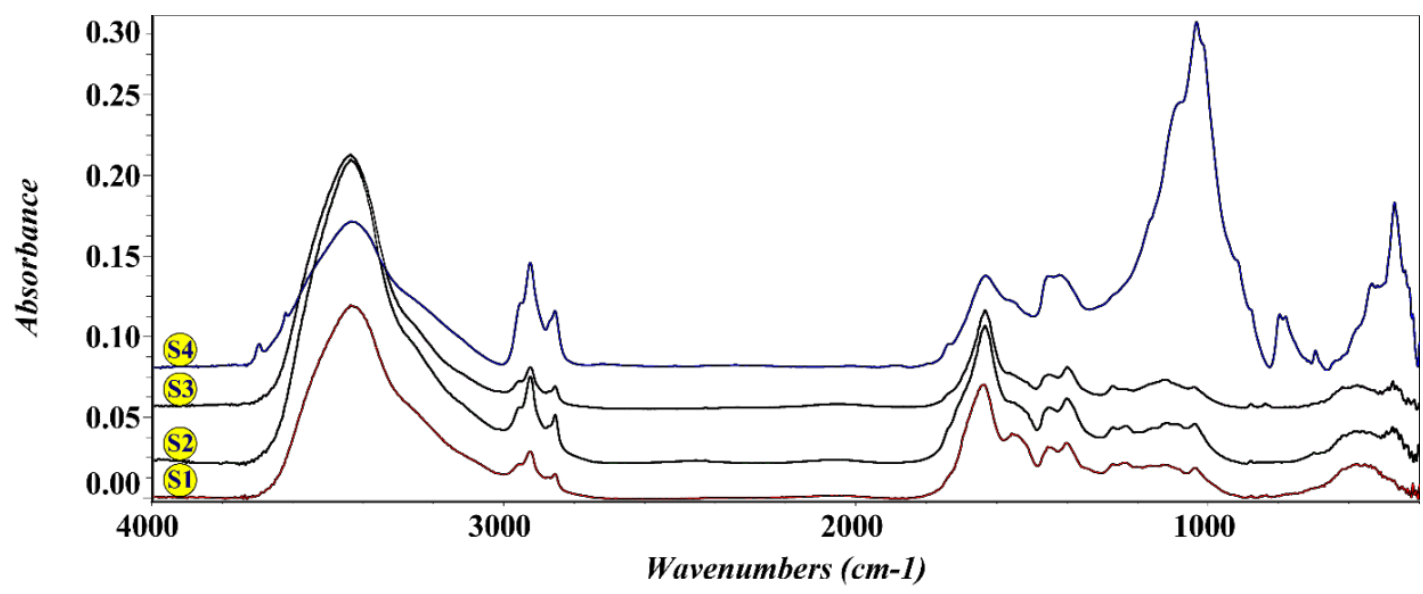

شكل ه: طيفهاى FTIR نمونههاى موردمطالعه از بخشهاى مختلف خرم

Fig. 5: FTIR spectra of leather samples

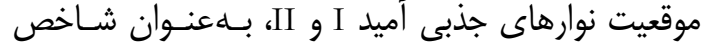
زلاتينه شدن كلازن (VA

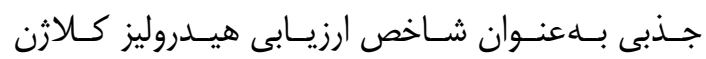

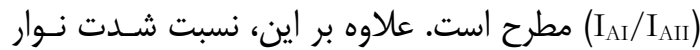

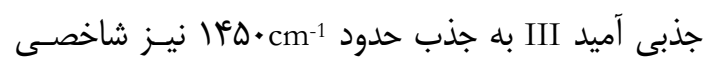
جهت ارزيابى دناتوره شدن كـلاثن (IIII كرفته مىشود. در حالت طبيعى vD در حدود

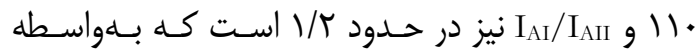

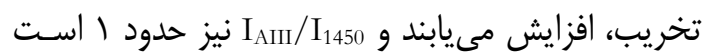

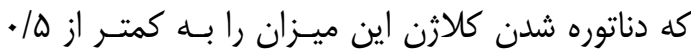
كاهش مىدهد [37-42]. علاوه بر اين اكسايش زنجيرههاى يلى يِيتيدى كـهـ

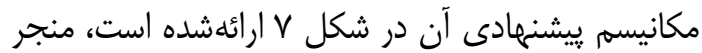
به تشكيل محصولات كربونيل دار مىشود كه نوار جذبى را در محدوده IVF•cme

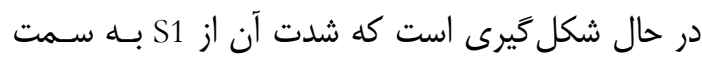

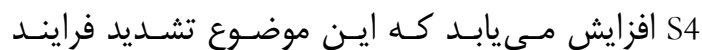
اكسايش را متناسب با ميـزان آهـن موجـود در سـاختار نشان مىدهد. در حقيقت حضور آهن، فراينـد اكسـايش

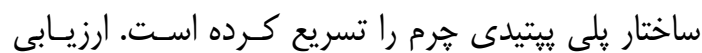

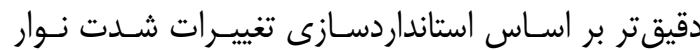

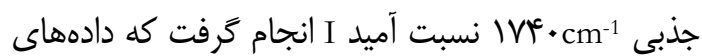
حاصل در جدول r ارائهشدهاند. آنجه مشخص استح سه نمونه بررسى شده، ICO/I متناسب با افزايش ميزان
شناخته مىشود [29]. حضـور ايـن سـاختار در نمونـــ S3،

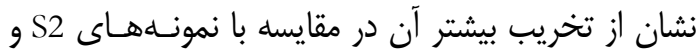

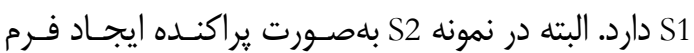

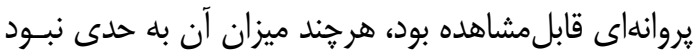
كه امكان بررسى اين شاخص تخريب را فراهم آوردا

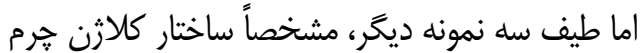

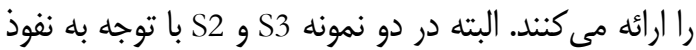

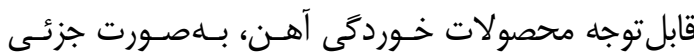

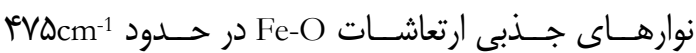

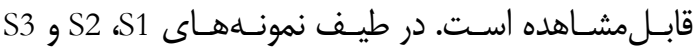

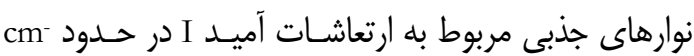

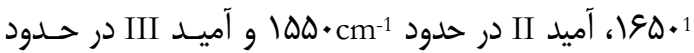

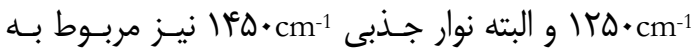

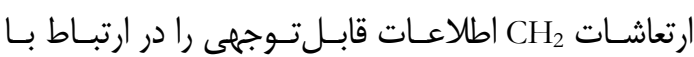
خصوصيات ساختارى كلاثن و هرم در اختيار قرار مىدهند

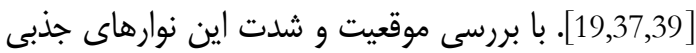

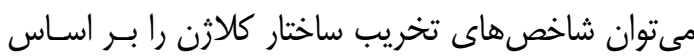

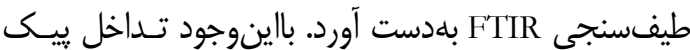
هاى موردمطالعه با يكديخر و همريوشـانى آنهـا، بررسى إنى

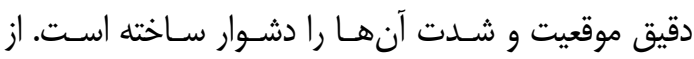
همين رو براى بررسى دقيقتر ييكهاى احتمالى موجود بر يايه شبيهسازى، از تابع گواسى استفاده شـد كـه نتـايج در شكل و قابل مشاهده هستند. در طيف FTIR سه شاخص هيدروليز، دناتوره شدن و زلاتينه شدن كلازثن قابـلبررسى اسـت. اخـتاف در در 

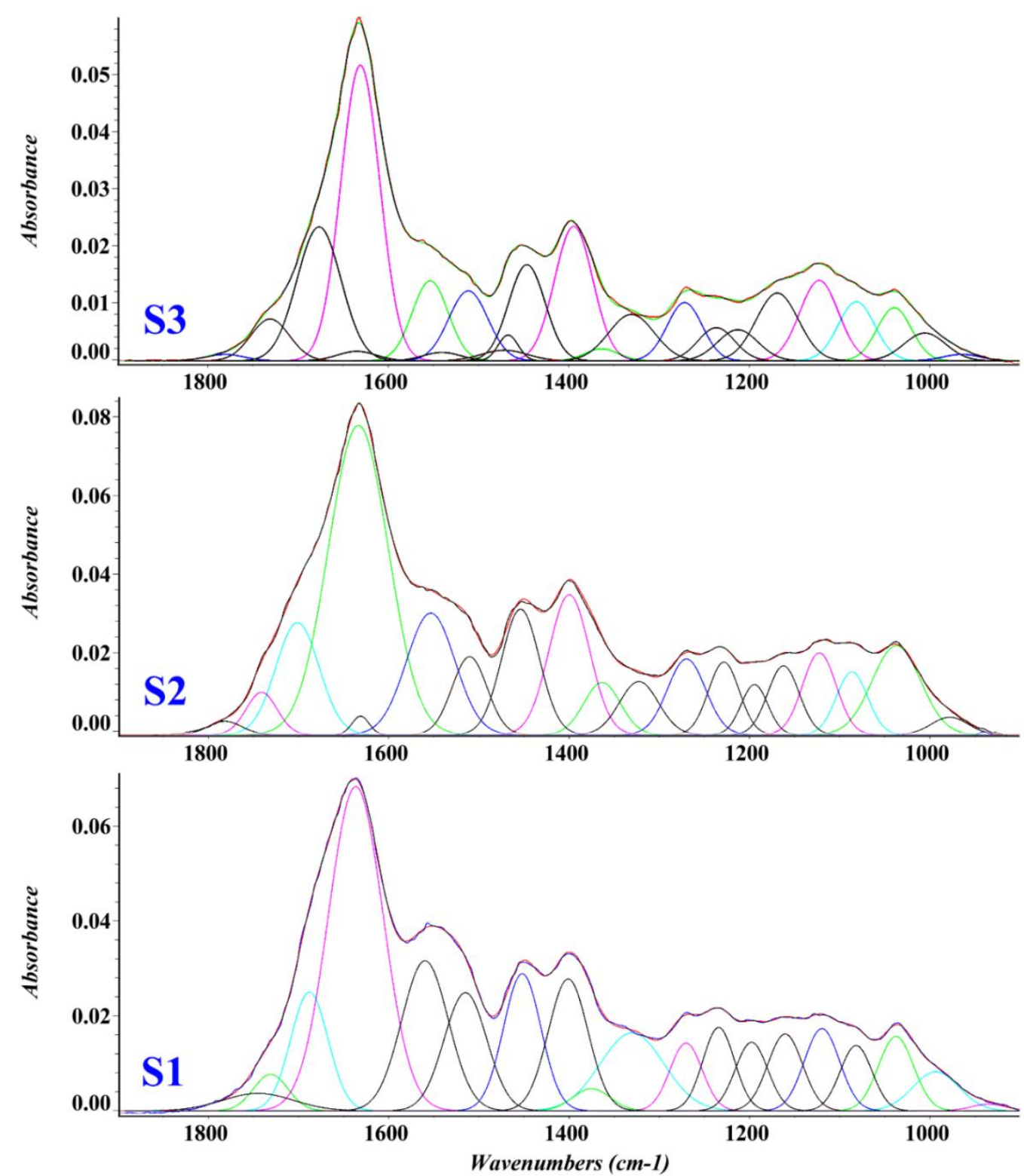

شكل צ: برازش طيفهاى FTIR نمونهها با استفاده از تابع گواسى پس از تصحيح خط زمينه در محدوده

Fig. 6: Gaussian fitted FTIR spectra of samples, baseline corrected in the region of $1900-900 \mathrm{~cm}^{-1}$
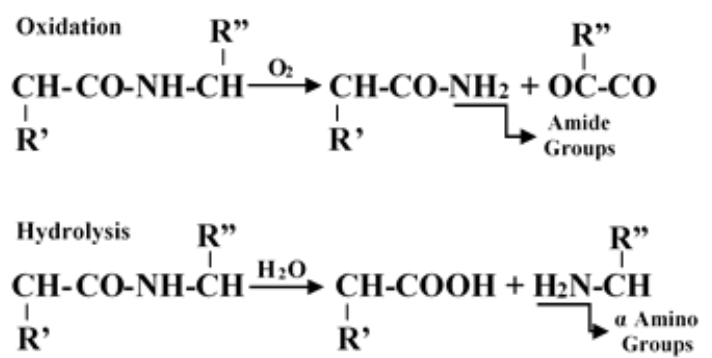

شكل V: مكانيسم اكسايش (بالا) و هيدروليز (يايين) ساختار كلاثن [If]

Fig. 7: The mechanism of oxidation and hydrolysis of collagen structure

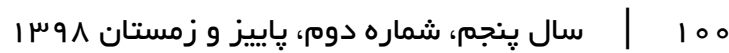


جدول r: شاخصهاى تخريب حاصل از طيفهاى FTIR نمونههاى جرم

Table 2: Degradation indices in FTIR spectra of leather samples

\begin{tabular}{|c|c|c|c|}
\hline \multicolumn{3}{|c|}{ Degradation indices/شمونn } & \multirow{2}{*}{$\begin{array}{c}\text { S } \\
\text { Sample }\end{array}$} \\
\hline $\mathrm{I}_{1740} / \mathrm{I}_{\mathrm{AI}}$ & $\mathrm{I}_{\mathrm{AIII}} / \mathrm{I}_{1450}$ & $\mathrm{I}_{\mathrm{AI}} / \mathrm{I}_{\mathrm{AII}}$ & $\mathrm{S} 1$ \\
\hline 0.11 & 0.61 & 2.17 & $\mathrm{~S} 2$ \\
\hline 0.13 & 0.58 & 2.60 & $\mathrm{~S} 3$ \\
\hline 0.14 & 0.34 & 3.74 & \\
\hline
\end{tabular}

در اين زمينه است. مطالعه بر روى بقاياى :جرمى مربـوط به محصولات كارخانه جرم خسروى تبريز كه در جريـان

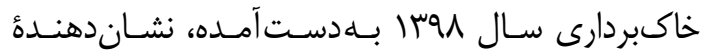
استفاده از نمكهاى كروم بلعنوان عامل دباغى و آهى بلعنوان عامل موزدايى در جريان فرآورى جرم بود. داده هاى حاصل، ميزان متفاوت تركيبات آهن در بخشهائ دراى

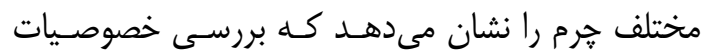

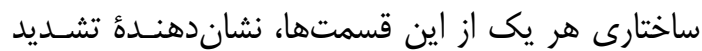

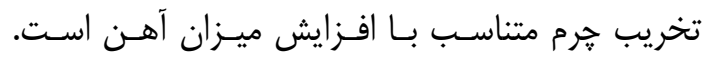

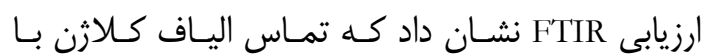

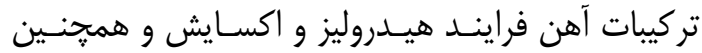

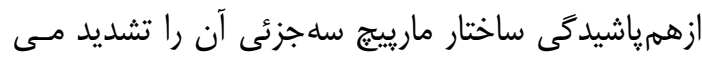

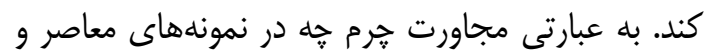

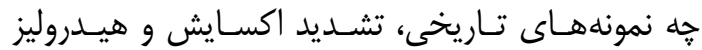

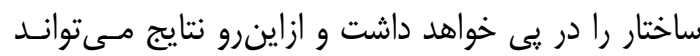

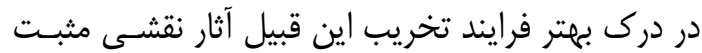

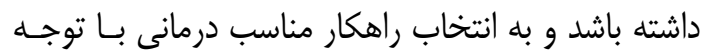

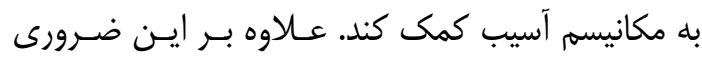

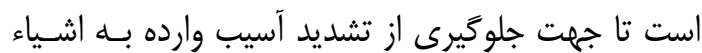

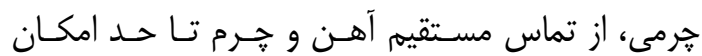
جلوكيرى كرد. همجنين بر اساس نتايج FTIR، تغييـرات ملموسى در شاخص زلاتينه شدن كلازن مشاهده نشد و بر اين اساس ارزيابى يايدارى هيـدروترمال در مطالعـات آتى، مى تواند نتايج فعلى را تكميل نمايد.

\section{سياسگَزارى}

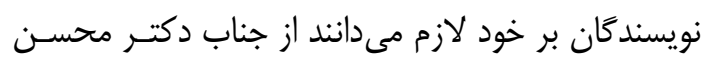

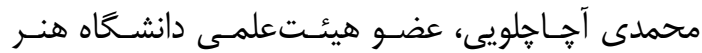

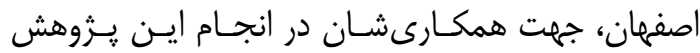
كمال تشكر و قدردانى را داشته باشند.
آهن، افزايش يافته است و بلهبــارتى ديخـر حضـور آهـن

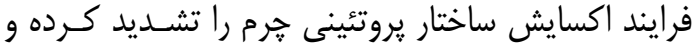

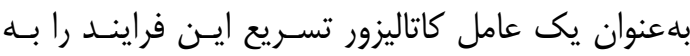
همراه داشته است. در بررسى VD، تغييرات محسوسى مشاهده نشـــ و

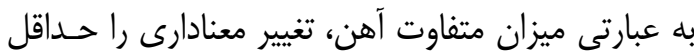

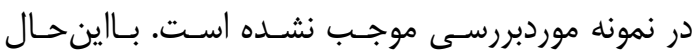
شاخص هيدروليز و يكيارجخى ساختار مارييج سـهزئسى

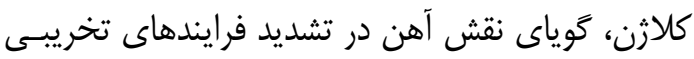

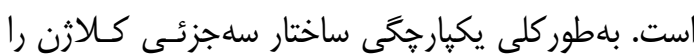

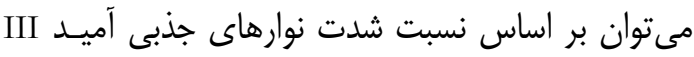

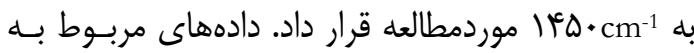
بررسى اين يارامتر در جدول r ارائهشدهاند كه در نمونـهـ

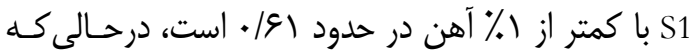

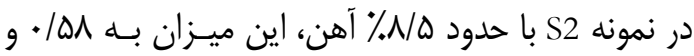

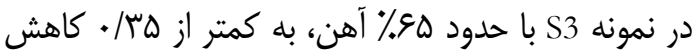
يافتهاست كه نشاندهنـــده تغييـرات اساسـى در سـاختار مارييج سلجزئى كلاثن و به عبارتى دناتوره شدن شـديد آن است. بررسى شدت هيدروليز اين سه نمونه نيـز داده

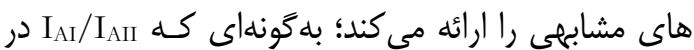

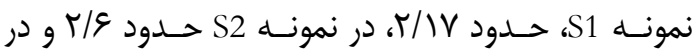

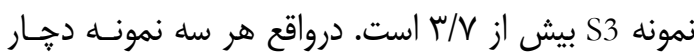

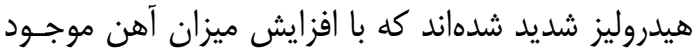
در ساختار، شدت اين هيدروليز نيز افزايشيافته است.

\section{ع. نتيجه كَيرى}

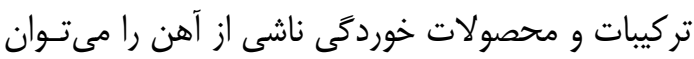

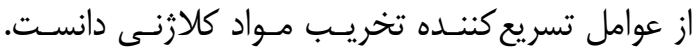
روشهاى متعددى جهت سنجش شـدت تخريسب مـواد كلازثنى بلويزه هرم وجود دارد كه در ايسن ميـان FTIR ابزارى مناسب جهت دستيابى به دادههايى قابـل اسـتناد

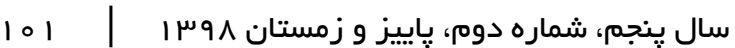




\section{References}

[1] Thomson, R., Leather, in Conservation Science: Heritage Materials, E. May and M. Jones, Editors. 2006, Cambridge: The Royal Society of Chemistry. p. 92-120.

[2] Fredericks, M., Progress in leather conservation. WAAC Newsletter, 1997. 19(2): p. 29-32. [doi.org/10.1016/S01964399(97)80006-2]

[3] Koochakzaei, A., Structural study of leather relics and assessment of softening and their treatment methods (Case study: a leather bottle attributed to the Seljuk period), M.A. thesis in conservation and restoration of historic and cultural property. 2013, Art University of Isfahan: Isfahan, Iran. [In Persian]

[4] Atkin, W.R. and F.C. Thompson, Proctor's Leather Chemists' Pocket Book. 3rd edition ed. 1937, London: E. \& E.N. Spon.

[5] Kanagy, J.R., Influence of Copper and Iron Salts on The Behavior of Leather in The Oxygen Bomb. Journal of research of the National Bureau of Standards, 1938. 20(6): p. 849-857. [doi.org/10.6028/jres.020.008]

[6] Bowes, J.H. and A.S. Raistrick, The Action of Heat and Moisture on Leather: Part I. The Storage of a Variety of Commercial Leathers at $40^{\circ} \mathrm{C}$ and 100 per Thousand R.H. Journal of the American Leather Chemists Association, 1961. 56(11): p. 606-615.

[7] Bowes, J.H. and A.S. Raistrick, The Action of Heat and Moisture on Leather. Part V. Chemical Changes in Collagen and Tanned Collagen. Journal of American Leather Chemists Association, 1964. 59(4): p. 201-215.

[8] Bowes, J.H. and A.S. Raistrick, The Action of Heat and Moisture on Leather. Part VI. Degradation of the Collagen. Journal of American Leather Chemists Association, 1967. 62(4): p. 240-257.

[9] Raistrick, A.S., The Action of Heat and Moisture on Leather. Part II. the Storage of Vegetable, Chrome, Semichrome, and Chrome Retan Leathers at Forty and Sixty Degrees Centigrade and 100 Percent R.H. for Varying Periods of Time. Journal of the American Leather Chemists Association, 1961. 56(11): p. 616-632.
[10] Bowes, J.H. and J.E. Taylor, Effect of Dry Heat on Collagen and Leather. Journal of American Leather Chemists Association, 1971. 66(3): p. 96-117.

[11] Larsen, R., et al., Amino Acid Analysis: Collagen in Vegetable Tanned Leather, in Environment Leather Project: Deterioration and Conservation of Vegetable Tanned Leather. 1997, The Royal Danish Academy of Fine Arts, School of Conservation. p. 39-68.

[12] Bowden, D.J. and P. Brimblecombe, The rate of metal catalyzed oxidation of sulfur dioxide in collagen surrogates. Journal of Cultural Heritage, 2003. 4(2): p. 137-147. [doi.org/10.1016/S1296-2074(03)000256]

[13] Creangă, D.M., The Inventory and Classification of Types of Damage to Objects From Ethnographic Collections. Codrul Cosminului, 2010. 16(2): p. 21-30.

[14] Lama, A., Antunes, A. P. M., Fletcher, Y., Guthrie-Strachan, J., \& Vidler, K., Investigation of acid-deterioration in leather leading towards finding a suitable product for treatment, in 114th Society of Leather Technologists and Chemists (SLTC) Conference. 2011: University of Northampton, Northampton, UK.

[15] Ohlídalová, M., Kučerová, I., Brezová, V., Cílová, Z., \& Michalcová, A., Influence of metal cations on leather degradation. Journal of Cultural Heritage, 2017. 24: p. 86-92. [doi.org/10.1016/j.culher.2016.10.013]

[16] Koochakzaei, A., H. Ahmadi, and S. Mallakpour, A review of the effect of copper and iron on deterioration of historical leathers, in 5th Iranian congress of trace elements. 2016 :Tarbiat Modares University, Tehran, Iran.

[17] Puica, N.M. and E. Ardelean, The industrial pollution impact on religious heritage in Romania. European Journal of Science and Theology, 2008. 4(2): p. 5159.

[18] Haines, B.M., Deterioration in leather bookbindings - our present state of knowledge. The Electronic British Library Journal, 1977. 3(1): p. 59-70.

[19] Koochakzaei, A. and M.M. Achachluei, Red Stains on Archaeological Leather: 
Degradation Characteristics of a Shoe from the 11th-13th Centuries (Seljuk Period, Iran). Journal of the American Institute for Conservation, 2015. 54(1): p. 45-56.

[doi.org/10.1179/1945233014Y.0000000 033]

[20] Duki, A., et al., The stability of metaltanned and semi-metal tanned collagen, in XXXII Congress of the International Union of Leather Technologists and Chemists Societies (IULTCS). 2013: Istanbul, Turkey.

[21] Haines, B.M., The Fibre Structure of Leather, in Conservation of Leather and Related Materials M. Kite and R. Thomson, Editors. 2006, ButterworthHeinemann: London. p. 11-21.

[22] Vogel, A.I. and G. Svehla, Textbook of Macro and Semimicro Qualitative Inorganic Analysis. 1979, London and New York: Longman Scientific \& Technical.

[23] Koochakzaei, A., H. Ahmadi, and M. Mohammadi Achachluei, A laboratory Analysis on a Seljuk Leather Bottle Found from Qhalee Kooh-i Qaen Excavation. Journal of Archaeological Studies, 2014. 5(2): p. 129-143. [In Persian]

[24] Cheng, M., Peng, W., Hua, P., Chen, Z., Sheng, J., Yang, J., \& Wu, Y., In situ formation of $\mathrm{pH}$-responsive Prussian blue for photoacoustic imaging and photothermal therapy of cancer. RSC Advances, 2017. 7(30): p. 18270-18276. [doi.org/10.1039/C7RA01879G]

[25] Gallhofer, D. and G.B. Lottermoser, The Influence of Spectral Interferences on Critical Element Determination with Portable X-Ray Fluorescence (pXRF). Minerals, 2018.2 8(8). [doi.org/10.3390/min8080320]

[26] Redus, R. Amptek Application Note XRF-1: XRF Spectra and Spectra Analysis Software. Application Note XRF-1 2008. DOI: https://amptek.com/pdf/xrf_2.pdf.

[27] Kolomazník, K., T. Fürst, and M. Bařinová, Non-linear diffusion model for optimization of leather manufacturing: Lime extraction from calcimine. Chemical Engineering Science, 2010. 65(2): $\quad$ p. 780-785.

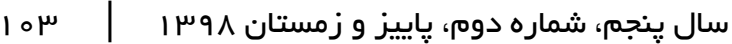

[doi.org/10.1016/j.ces.2009.09.030]

[28] Covington, A.D., Tanning Chemistry: The Science of Leather. 2009: Royal Society of Chemistry.

[29] Mühlen Axelsson, K., R. Larsen, and D.V.P. Sommer, Dimensional studies of specific microscopic fibre structures in deteriorated parchment before and during shrinkage. Journal of Cultural Heritage, 2012. 13(2): p. 128-136. [doi.org/10.1016/j.culher.2011.08.001]

[30] Mühlen Axelsson, K., Larsen, R., Sommer, D. V. P., \& Melin, R., Establishing the relation between degradation mechanisms and fibre morphology at microscopic level in order to improve damage diagnosis for parchments - A preliminary study, in ICOM-CC 18th Triennial Conference Preprints, J. Bridgland, Editor. 2017, Paris: International Council of Museums: Copenhagen.

[31] Vila, A. and J.F. García, Analysis of the Chemical Composition of Red Pigments and Inks for the Characterization and Differentiation of Contemporary Prints. Analytical Letters, 2012. 45(10): p. 12741285. [doi.org/10.1080/00032719.2012.673100]

[32] Rezende, J. C. T., Ramos, V. H. S., Oliveira, H. A., Oliveira, R. M. P. B., \& Jesus, E., Removal of $\mathrm{Cr}(\mathrm{VI})$ from Aqueous Solutions Using Clay from Calumbi Geological Formation, N. Sra. Socorro, SE State, Brazil. Materials Science Forum, 2018. 912: p. 1-6. [doi.org/10.4028/www.scientific.net/MS F.912.1]

[33] Namduri, H. and S. Nasrazadani, Quantitative analysis of iron oxides using Fourier transform infrared spectrophotometry. Corrosion Science, 2008. 50(9): p. 2493-2497. [doi.org/10.1016/j.corsci.2008.06.034]

[34] Salama, W., M. El Aref, and R. Gaupp, Spectroscopic characterization of iron ores formed in different geological environments using FTIR, XPS, Mössbauer spectroscopy and thermoanalyses. Spectrochimica Acta Part A :Molecular and Biomolecular Spectroscopy, 2015. 136: p. 1816-1826. [doi.org/10.1016/j.saa.2014.10.090] 
[35] Makó, É., Kovács, A., Katona, R., \& Kristóf, T., Characterization of kaolinitecetyltrimethylammonium chloride intercalation complex synthesized through eco-friend kaolinite-urea preintercalation complex. Colloids and Surfaces A: Physicochemical and Engineering Aspects, 2016. 508: p. 265273.

[doi.org/10.1016/j.colsurfa.2016.08.035]

[36] Lu, B., Surface Reactivity of Hematite Nanoparticles, in Department of Chemistry. 2014, Umeå University: Umeå, Sweden.

[37] Vyskočilová, G., Ebersbach, M., Kopecká, R., Prokeš, L., \& Př́íhoda, J., Model study of the leather degradation by oxidation and hydrolysis. Heritage Science, 2019. 7(1): p. 26. [doi.org/10.1186/s40494-019-0269-7]

[38] Koochakzaei, A., H. Ahmadi, and S. Mallakpour, An experimental comparative study of the effect of skin type on the stability of vegetable leather under acidic condition .Journal of the American Leather Chemists Association,
2018. 113(11): p. 345-351.

[39] Koochakzaei, A., H. Ahmadi, and M. Mohammadi Achachluei, An experimental comparative study on silicone oil and polyethylene glycol as dry leather treatments. Journal of the American Leather Chemists Association, 2016. 111(10): p. 377-383.

[40] Badea, E., Miu, L., Budrugeac, P., Giurginca, M., Mašić, A., Badea, N., \& Della Gatta, G., Study of deterioration of historical parchments by various thermal analysis techniques complemented by SEM, FTIR, UV-Vis-NIR and unilateral NMR investigations. Journal of Thermal Analysis and Calorimetry, 2008. 91(1): p. 17-27. [doi.org/10.1007/s10973-0078513-x]

[41] Derrick, M., Evaluation of the State of Degradation of Dead Sea Scroll Samples Using FTIR Spectroscopy. The book and paper annual, 1991. 10: p. 49-65.

[42] Carșote, C., Damage assessment of historical leathers and parchments, in Department of Chemistry. 2017, University of Bucharest. 